\title{
Design and Performance of Low Reynolds Number Airfoils for Solar-Powered Flight
}

\author{
Weisheng Chen ${ }^{1}$ and Luis P. Bernal ${ }^{2}$ \\ University of Michigan, Ann Arbor, Michigan, 48109, USA
}

\begin{abstract}
Airfoils with flat panels on the suction side and a flat pressure side are investigated for use with flat solar arrays for low speed solar-powered flight. Over 200 designs were evaluated using a coupled panel method/boundary layer analysis code (Drela, M., "XFOIL: An Analysis and Design System for Low Reynolds Number Airfoils," in Conference on Low Reynolds Number Aerodynamics, June 1989). The best four designs were fabricated and their aerodynamic performance measured experimentally for design validation. Experimental aerodynamic analysis was conducted in the 2 ' $\mathbf{2} 2$ ' wind tunnel at the University of Michigan, Ann Arbor. The lift was measured using a force balance over a range of angles of attack from -5 to 20 degrees and at four Reynolds numbers: $60,000,100,000,200,000$ and 250,000 . The airfoils drag was determined from wake velocity profiles measured using twodimensional Particle Image Velocimetry at Reynolds numbers of 60,000 and 250,000 . The flow over the suction side of the airfoils was also examined for laminar separation bubbles using Particle Image Velocimetry. The aerodynamic performance of the airfoils is compared to that of a SD 7080 airfoil, which is an airfoil section frequently used in low Reynolds number applications. The airfoil section that showed best performance is the BC 3X92, which has three flat panels on the suction side and a maximum thickness of 9.2 percent. Its drag is comparable to that of the SD 7080, and has comparable or higher maximum lift coefficient. The $\mathrm{BC}$ airfoils with flat panels typically generate more lift than the SD 7080 at almost all angles of attack because of the larger mean camber. From the flow field data, regions of separated flow and laminar separation bubbles are identified at a Reynolds number of 60,000 , but none is observed at a Reynolds number of 200,000 . The measured lift curves and the location of laminar separation bubbles of the $\mathrm{BC}$ airfoils are compared to XFOIL estimates. Such comparisons show that XFOIL predicts the trends of the lift curve well, especially at the higher Reynolds numbers. However, XFOIL predicts many features in the lift curve that are not observed on the measured lift curves perhaps due to the unconventional airfoil geometry used in this study. In particular, XFOIL consistently predicts the formation of laminar separation bubbles at most angles of attack, which were not found in the experiments.
\end{abstract}

\footnotetext{
${ }^{1}$ Graduate Student, currently at DSO National Laboratories, Address: 20 Science Park Drive, Singapore 118230, SINGAPORE, AIAA Member

${ }^{2}$ Associate Professor, Department of Aerospace Engineering, Address: 1320 Beal Avenue, Ann Arbor, MI 481092140, AIAA Senior Member 


\section{Introduction}

$\mathrm{S}_{\mathrm{n}}^{\mathrm{o}}$ olar-powered air vehicles have become increasingly popular due to advances in solar-cells, composite manufacturing, and unmanned autonomous aircraft technologies. A solar-powered platform that efficiently stores and uses solar energy could provide a viable alternative for long endurance missions that require sustained flight. Solar-powered flight was demonstrated in the 1970's. ${ }^{1,2}$ The current aerodynamic design trend gravitates toward the use of conventional, low camber airfoils that provide reasonable aerodynamic performance and have gentle curving surfaces that allow for encapsulated solar-cells to be bent along its contour. An alternative concept first proposed by McCready et al. ${ }^{2}$ is to design airfoils with flat panels that allow for flat solar arrays to be mounted on the airfoil. This approach is motivated by the fact that high efficiency solar cells are made of crystalline materials that are very brittle and cannot be easily shaped into a smooth aerodynamic contour. Currently, only the LissamanHibbs 8025 and 8230 are airfoils with significant flat surfaces specifically designed for solar-power applications. ${ }^{1,2}$ However, very little information is available, such as the detailed shape of these airfoils. The Wortmann airfoils have also been considered for high-altitude solar-powered platforms, ${ }^{3}$ but they are highly cambered near its hooklike trailing edge, representing a challenge for manufacturing.

By using a flat-paneled airfoil, the loss of solar-cell efficiency attributed to bending during encapsulation can be avoided. The mounting of flat arrays and fabrication of such an airfoil would be simpler while the flat arrays could be easily aligned to the sun during flight to sustain solar panel output. This would reduce efficiency losses that are known to occur due to irradiance differences over a curved solar array. ${ }^{4}$ Also, with the current methodology of bending the solar array, the exact airfoil shape might be compromised due to limitations on the flexibility of the cells and manufacturing technique, leading to a loss in aerodynamic efficiency. Alternative solar films that are available off-the-shelf could be used but they have much lower efficiencies compared to multi-junction solar cells. The airfoils discussed here have flat surfaces on them that amount to more than $60 \%$ of the chord length. Moreover, the bottom surfaces of the airfoils are flat and can be used to mount additional solar cells to collect Earth albedo radiation for additional solar-energy harvesting.

Of particular interest is the performance of airfoils for solar-powered flight at low Reynolds number. Recent advances in microelectronics and embedded sensor systems enable the development of small platforms for sensor deployment. Solar power can provide a viable energy source for very long endurance flight. These platforms can be expected to be small and fly at relatively low speeds (i.e. low Reynolds number) to minimize power requirements. At these conditions, laminar separation bubbles and laminar to turbulent transition are pervasive and play a critical role in the aerodynamics of airfoils. Design methodologies at these conditions present unique challenges and need to be carefully validated. In this paper the design methodology and selection criteria of suitable airfoils for testing are presented first, followed by the results of the experimental analysis of selected airfoils. The various airfoil designs were evaluated using a widely-available airfoil analysis software package, XFOIL ${ }^{5,6}$. The aerodynamics of the selected airfoils is studied experimentally using direct force measurements and two-dimensional Particle Image Velocimetry (PIV). The PIV measurements are used to determine the drag of the airfoils and the separated flow regions on the suction side of the airfoils. The experimental results are also compared to the aerodynamic performance obtained using XFOIL to validate the predictions for the present very unique airfoil sections.

\section{Design Methodology and Airfoil Selection}

There was no pre-defined starting point for the design due to the lack of information on previous airfoils designed for solar-power applications. It was unclear where the optimum location of a flat panel will be on an airfoil. With the availability of inverse-design codes, ${ }^{5}$ the design of an airfoil could be done in an "inverse" manner by specifying the surface pressure/speed distribution that would determine the shape. However, this was deemed to be inappropriate due to the desire to have a truly flat surface and it is unclear what the pressure/speed distribution of a randomly oriented flat panel within an airfoil would be. Therefore, a trial-and-error approach was adopted based on basic building blocks of an airfoil's geometry. We initiated our design based on a conventional airfoil that is often used for remote-controlled aircrafts, and has reasonable aerodynamic performance. The selected airfoil was the SD 7080.

The building blocks that were used to shape our airfoils consisted of an ellipse for the nose of the airfoil, flat panels and circular arc sections between the flat panels; the bottom surface of the airfoil is also kept flat after the nose segment. An ellipse is a common shape used for aerodynamic bodies and it is also easy to specify. A Matlab $\odot$ code was written to aid the generation of a desired airfoil geometry based on different combinations of these building blocks. 213 different configurations were considered by varying the span of the nose, flat panels size and radii-of-curvatures of the circular arc sections, by changing the aspect ratio of the elliptical nose or by varying the 
number of flat panels and the angle with which the nose and flat panels are oriented with respect to each other. These variations were systematically introduced so that the trends in changing a specific parameter, such as the span of the nose, could be determined. The performance of each configuration was examined using the XFOIL program. ${ }^{6}$ Once a trend has been established, the optimum setting of the specific parameter is kept while the effects of varying another parameter are studied. Fig. 1 illustrates the different design controls used to vary the airfoil geometry.

The various configurations could be classified into three different classes of airfoils: Airfoils with three flat panels, airfoils with two flat panels and symmetrical airfoils with flat panels. Airfoils with one flat panel did not show good performance mainly due to the fact that the bottom surface of the airfoil was constrained to be flat too. This meant that the resultant trailing edge angle would be large or the nose would need to be fairly thick, which creates problems for the flow over the airfoil at high angles of attack. For the wind tunnel tests, one airfoil from each category was chosen and in addition, an airfoil with similar thickness as the SD 7080 was also chosen. In

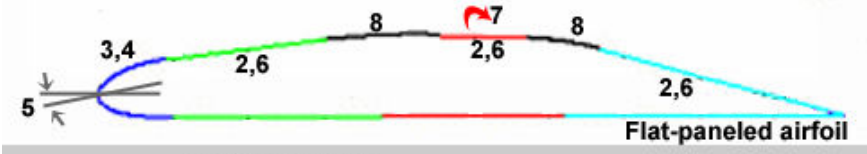

Design controls:

1. Symmetrical or cambered airfoil

2. Number of flat panels

3. Span of the nose

4. Aspect ratio of the nose

5. Rotation of nose

6. Span of each individual panel

7. Rotation of intermediate panel

8. Radii of curvatures

Figure 1. Design controls for flat-paneled airfoil.

total, we manufactured four airfoils. In the selection of the airfoils, a scoring matrix was devised, which compared the performance of the four most promising airfoils in each category to the performance of the SD 7080. The scoring matrix is based on the following criteria:

1. $\mathrm{C}_{\mathrm{l}} / \mathrm{C}_{\mathrm{d}}$ at cruise compared to that of the SD 7080

2. $\mathrm{C}_{1}$ at cruise compared to that of the SD 7080

3. $\mathrm{C}_{\mathrm{d}}$ at cruise compared to that of the SD 7080

4. $\mathrm{C}_{1}$ at stall compared to that of the SD 7080

5. $\mathrm{V}_{\text {cruise }} / \mathrm{V}_{\text {stall }}$

This scoring system was not applied to the symmetrical airfoils since they have different performance characteristics compared to the cambered airfoils. The cruise angle of attack of the airfoils was established at the angle of attack with the highest $C_{1} / C_{d}$ ratio, which is often associated with the design lift coefficient. ${ }^{7}$ The choice of the first four evaluation criteria is obvious and follows conventional evaluation criteria for airfoil aerodynamic performance. The final criterion of the ratio of the velocity at cruise compared to that at stall gives a sense of the operating margin between cruise and stall. The four most promising airfoils in each category were scored, the best performing airfoil receives a score of four points; the second best gets three points and so on. All airfoils were assessed at a Reynolds number of 250,000. The following table presents the scores of the different airfoils considered. The nomenclature of the airfoil names can be broken down to: $\mathrm{BC}$ denotes that these airfoils are designed by the two authors of this paper. Next, the first digit represents the number of flat panels on the top surface of the airfoil and the next three digits represent its thickness (for example, 111 indicates that the airfoil is $11.1 \%$ thick and X92 is used to indicate that the airfoil is $9.2 \%$ thick) and the letter "S" denotes a symmetrical airfoil.

Based on this scoring system, the best airfoil with three flat panels was the $\mathrm{BC} 3111$ configuration while the best airfoil with two flat panels was the BC 2125 configuration, as shown in Table 1. In addition, the BC 3 X92 airfoil with three flat panels was also selected for subsequent testing because it has a thickness of $9.2 \%$ that matches the thickness of the SD 7080 airfoil and comparing these two airfoils are of interest. It is noted that the $\mathrm{BC} 3 \mathrm{X} 92$ airfoil was the second best airfoil evaluated in the three panels category. For the symmetrical airfoil category,
$\mathrm{C}_{\mathrm{l}} / \mathrm{C}_{\mathrm{d}} @$ cruise $\mathrm{C}_{1} @$ cruise $C_{d} @$ cruise $\mathrm{C}_{1} @$ stall $\mathbf{V}_{\text {cruise }} / \mathbf{V}_{\text {stall }}$ Total score

\begin{tabular}{|c|c|c|c|c|c|c|c|}
\hline \multicolumn{4}{|c|}{ 3-panels } & \multicolumn{4}{|c|}{ 2-panels } \\
\hline$\underset{\infty}{=}$ & 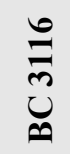 & 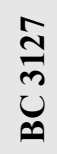 & 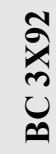 & 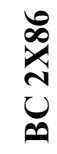 & 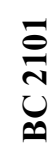 & $\underset{n}{\stackrel{1}{N}}$ & 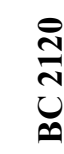 \\
\hline 4 & 1 & 2 & 3 & 2 & 3 & 4 & \\
\hline 3 & 1 & 4 & 2 & 3 & 2 & 4 & \\
\hline 3 & 2 & 1 & 4 & 1 & 4 & 3 & \\
\hline 3 & 1 & 4 & 2 & 1 & 3 & 4 & 2 \\
\hline 3 & 4 & 1 & 2 & 2 & 3 & 1 & 4 \\
\hline 16 & 9 & 12 & 13 & 9 & 15 & 16 & \\
\hline
\end{tabular}

Table 1. Airfoil selection criteria and scoring. the BC S127 airfoil was selected. The following plots show the performance of each airfoil (evaluated in XFOIL) in each of the five categories scored in 
Table 1. The performance of the SD 7080 airfoil is also shown as a benchmark for the performance of the newlydesigned airfoils.
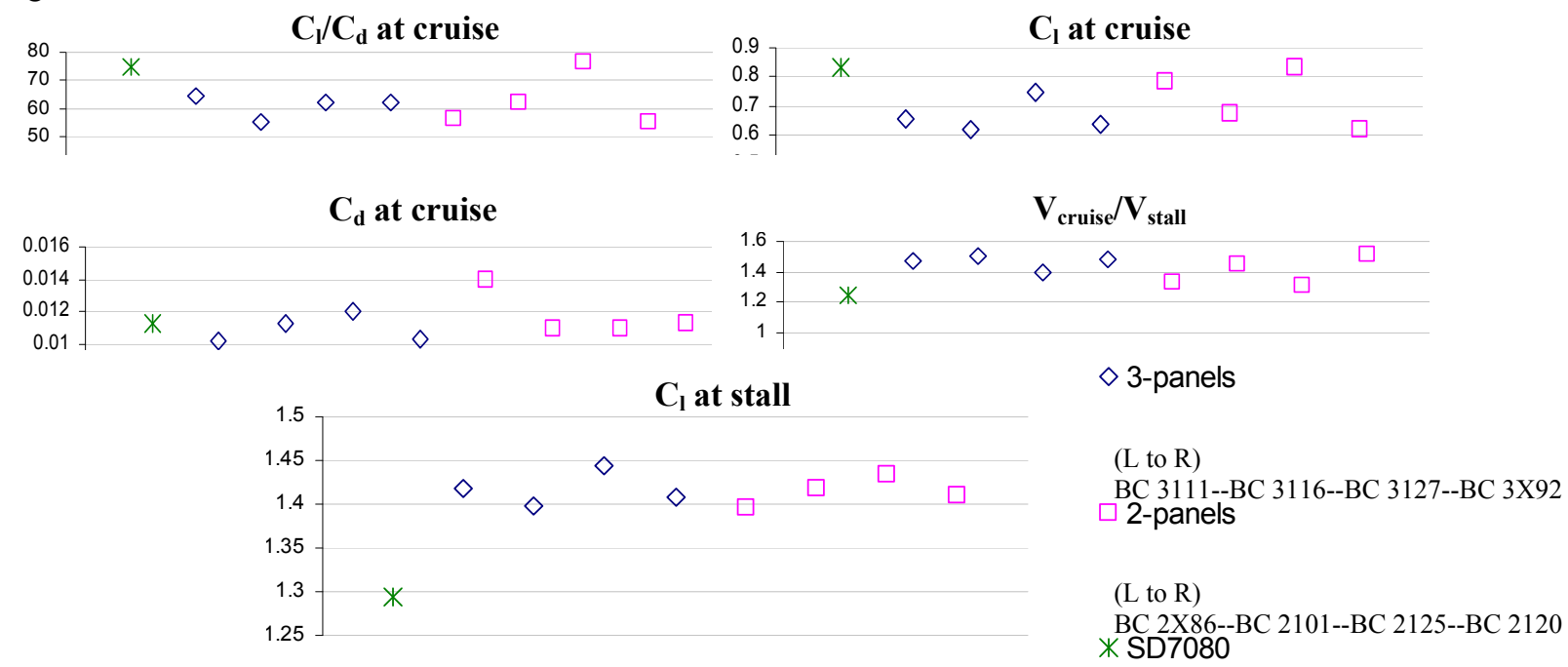

Figure 2. The five criteria used to score the eight newly-designed airfoils. The airfoils are divided into two groups, the airfoils with three flat panels and those with two flat panels. The legend states the order of the airfoils represented by the data points in each plot.

The geometry of all four selected airfoils is shown in Fig. 3 and that of the SD 7080 is also shown.

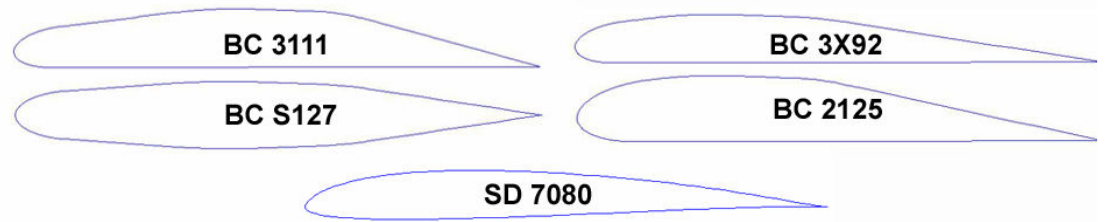

Figure 3. The four selected airfoils and the SD 7080 airfoil.

\section{Experimental Setup and Data Acquisition}

The manufacturing and testing of the airfoils were performed at the University of Michigan, Ann Arbor. All the airfoil models had a chord of 6.3 inches and a span of 23.5 inches. The airfoils were then measured at its mid-span location using a Brown \& Sharpe coordinate measuring machine. By plotting the measured coordinates and the designed airfoil, the shape and form of the manufactured airfoils were determined to conform closely. The accuracy of the manufacturing was evaluated by comparing the measured thickness along the chord of the airfoil with that of the designed airfoil. The average of all the variation in the thickness was calculated and the highest average deviation was not more than 0.015 inches.

The airfoils were tested at the Aerospace Engineering department's low-speed, open-return wind tunnel. The wind tunnel has a test section 2 feet wide by 2 feet high and 8 feet long. Upstream of the test section is a series of honeycombs and three turbulence reducing screens in the settling chamber that helps to homogenize the flow. The tests were conducted over a range of speeds from 6-24 meters per second (14-54 miles per hour) to achieve the desired Reynolds number in each of the test cases. The measured turbulence intensity in the wind tunnel, whose schematic is shown in Fig. 4, was less than $0.25 \%$. Two separate setups were used; one for the lift force measurement and the other for the PIV

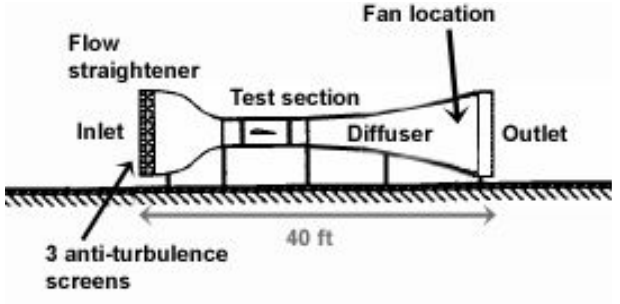

Figure 4. Schematic of the University of Michigan, Aerospace Engineering 2'x2' wind tunnel.

measurements. The lift force was measured via a force balance setup that made use of two load transducers, 
calibrated before the start of each test. The force balance was then removed and the optics required for the PIV measurements were installed; the data was acquired on two personal computers via a PCOC high-resolution camera, equipped with four gigabytes of onboard memory. Fig. 5 shows the setup for the PIV testing.

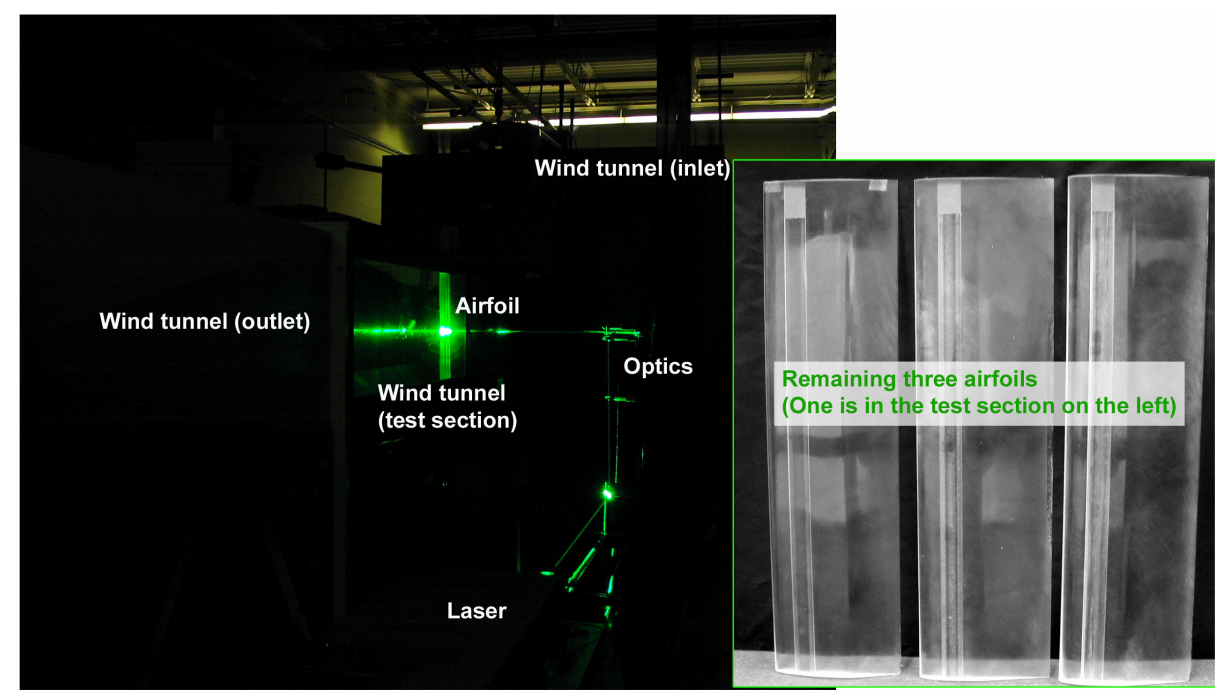

Figure 5. Wind tunnel setup for the PIV experiments. The force balance setup has been removed from its position directly above the airfoil in the test section.

The airfoils' drag was derived from PIV velocity measurements in the wake of the airfoils. Mean velocity profiles in the wake were obtained at $1.25,1.5$ and 1.75 chord-lengths downstream of the trailing edge, and the drag calculated for the three downstream locations averaged. Finally, PIV measurements were made over the suction side of the airfoils to determine the flow characteristics over the airfoils. Typical interrogation window size used in the analysis of the PIV images was $1.2 \mathrm{~mm} \times 0.6 \mathrm{~mm}$. The airfoils were manufactured of acrylic and polished to remove light-scattering imperfections thus eliminating surface glare. The PIV images had very little glare at the airfoil surface and PIV velocity data could be obtained very close to the surface, well within the boundary layer. Two high resolution images are shown in Fig. 6. They are typical of the PIV image data used in this study.

\section{Results and Discussion}

The experimental results presented here include the lift and drag characteristics of the airfoils, and features of the flow over the suction side of the airfoils. Two load transducers, each having a maximum load limit of 25 pounds-force, were used to obtain the lift data. The data were measured from -5 to 20 degrees angle of attack, at one degree increment. The uncertainty of these data was estimated from the standard error in the calibration results and is given in Table 2.

The PIV measurements allowed for accurate flow characterization in the wake as well as over the suction side of the airfoils. The uncertainties of the drag results
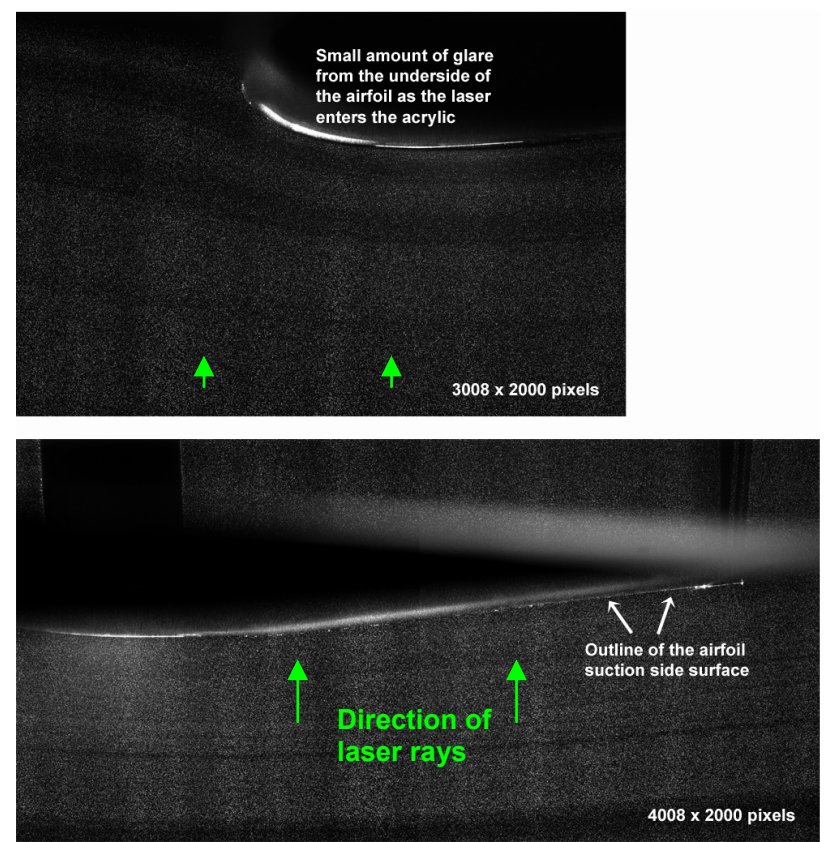

Figure 6. Two separate images from PIV tests. The top image shows a capture of the leading edge to more than 40\%-chord and the bottom one shows a capture about 20\%-chord to the trailing edge. The size of the top image was deliberately reduced to minimize the time required for data acquisition, transmission and storage, which is significant due to the large number of images taken. Sufficient seeding of the flow with smoke particles is evident in both images. 
based on the PIV mean velocity wake surveys were estimated using the standard error in the data. Due to the large amount of time and effort required, wake measurements were only conducted at four angles of attack, at two Reynolds numbers, and at three different downstream locations for each airfoil. Detailed PIV flow field measurements on the suction side of each airfoil were obtained at three angles of attack, and two Reynolds numbers.

\section{A. Lift Characteristics of the BC Airfoils}

Using the force balance, the lift of the four airfoils was measured, at four different Reynolds numbers $(60,000$, $100,000,200,000$ and 250,000). The plots of the lift curve over a range of angles of attack are shown below in Figures 7 through 10. The standard error in the lift coefficient, $\mathrm{C}_{1}$, at each of the Reynolds number is given in Table 2 and is not shown in the figures.

The BC 2125 airfoil shows a fairly constant lift curve slope throughout, which is comparable to the classical lift curve slope, as seen in Fig. 7. The stall $\mathrm{C}_{1}$ improves from 1.1 at 60,000 Reynolds number to about 1.6 at and above 200,000 Reynolds number. The stall characteristic at Reynolds numbers of 60,000, 100,000 and 200,000 features a fairly significant drop in $\mathrm{C}_{1}$ at angles of attack of 9,12 and 16 degrees respectively.

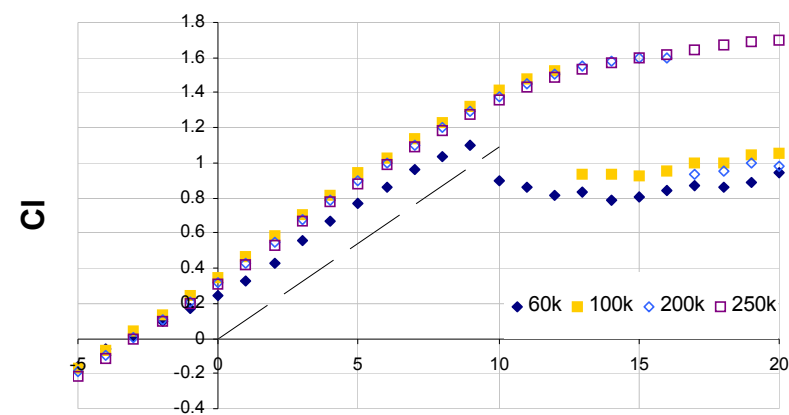

AOA(deg)

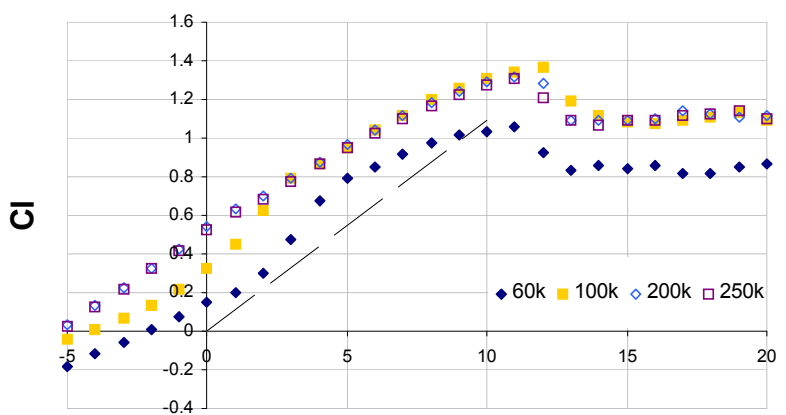

AOA(deg)

Figure 7. Lift curves for the BC 2125 airfoil. The Figure 8. Lift curves for the BC 3111 airfoil. The linear-theory lift curve slope $\left(2 \pi \mathrm{rad}^{-1}\right)$ is shown as a linear-theory lift curve slope $\left(2 \pi \mathrm{rad}^{-1}\right)$ is shown as a broken line for comparison. broken line for comparison.

The BC 3111 airfoil shows that the lift curve slope changes at low Reynolds numbers of 60,000 and 100,000, as seen in Fig. 8. Generally, the lift curve slope is less than $2 \pi$ but it increases between 2-4 degrees angle of attack. The stall characteristic of this airfoil features a moderate drop in the $C_{1}$ and stall occurs around 11-12 degrees angle of attack. The stall $\mathrm{C}_{1}$ ranges from about 1.1 to 1.4 in the range of Reynolds number tested.

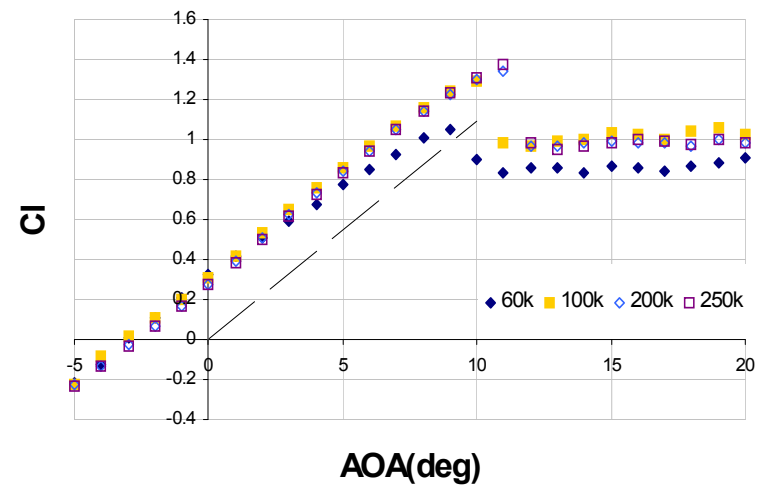

Figure 9. Lift curves for the BC 3X92 airfoil. The linear-theory lift curve slope $\left(2 \pi \mathrm{rad}^{-1}\right)$ is shown as a broken line for comparison.

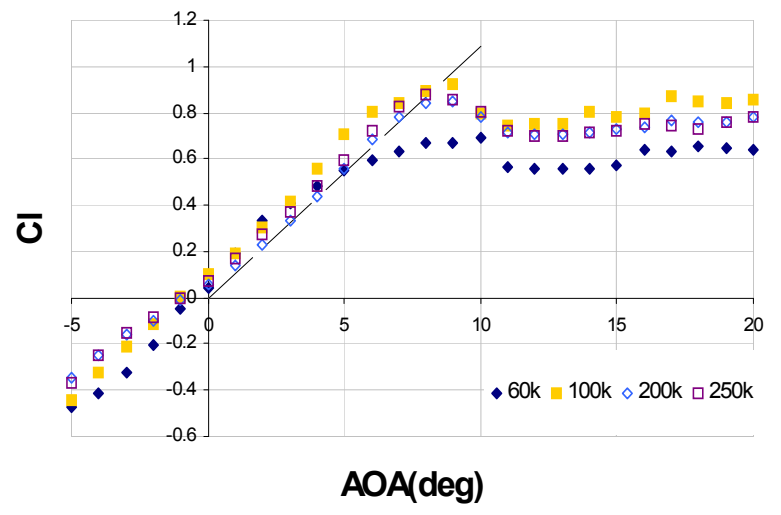

Figure 10. Lift curves for the BC S127 airfoil. The linear-theory lift curve slope $\left(2 \pi \mathrm{rad}^{-1}\right)$ is shown as a broken line for comparison. 
The BC 3X92 airfoil lift coefficient results shown in Fig. 9 feature a fairly straight lift curve slope that is slightly lower than the linear theory result. Stall $C_{1}$ ranges from about 1.1 to 1.4. Stall involves a moderate drop in $C_{1}$ and occurs between 9-11 degrees angle of attack. The symmetrical BC S127 airfoil stalls at less than 10 degrees angle of attack as shown in Fig. 10. Generally, the lift curve slope is close to the linear theory value. Stall is gentle and the drop in $C_{1}$ is not as drastic as those seen in the cambered airfoils. However, the stall $C_{1}$ is significantly lower that for the cambered airfoils in the range from 0.7 to about 0.9 for the Reynolds numbers investigated.

Finally, lift data for the SD 7080 airfoil reported in the litereature ${ }^{8}$ and compared to the four BC airfoils' lift data for the Reynolds numbers of 60,000, 100,000 and 200,000. The lift of the cambered flat-paneled airfoils (BC 2125, $\mathrm{BC} 3111$ and $\mathrm{BC} 3 \mathrm{X92}$ ) are comparable to the SD 7080's at the low Reynolds number of 60,000. At higher Reynolds numbers of 100,000 and 200,000, the cambered flat-paneled airfoils generally generate more lift than the SD 7080, and the stall $C_{1}$ is significantly larger. The symmetrical flat-paneled airfoil, the BC S127, have more modest lift and stall characteristics compared to the SD 7080. The comparisons are shown in Fig. 11.
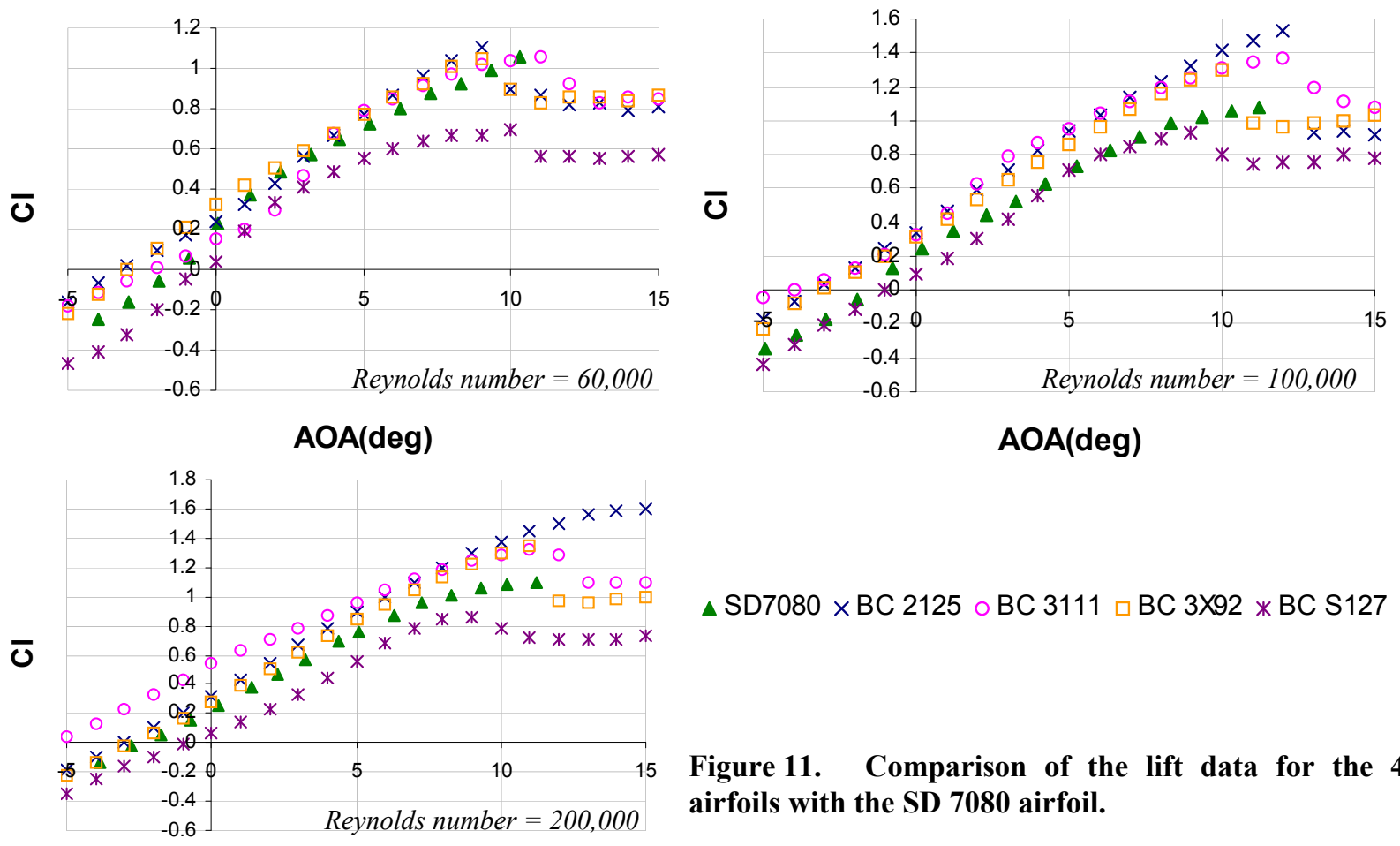

$\triangle \mathrm{SD} 7080 \times \mathrm{BC} 2125 \circ \mathrm{BC} 3111 \square \mathrm{BC} 3 \mathrm{X92} * \mathrm{BC}$ S127

These data show that the cambered BC airfoils match conventional airfoils such as the SD 7080 in terms of lift. At the higher Reynolds number of 200,000, the cambered BC airfoils produce more lift than the SD 7080 with a comparable lift curve slope. From the perspective of lift, it is plausible to replace conventional airfoils on solarpowered platforms with one of the above-mentioned $\mathrm{BC}$ airfoils.

\section{B. Drag Characteristics of the BC Airfoils}

The drag of the airfoils was calculated from the velocity deficit in the wake profiles at different downstream locations, at the mid-span of the wing. The average of the drag calculated at 1.25, 1.5 and 1.75 chords downstream of the trailing edge was used to account for the effect of variations in the free-stream velocity. The measurement uncertainty in the $C_{d}$ values is not higher than 0.001 for both Reynolds numbers. The plots in Fig. 12 compare the $C_{d}$ of the newly-designed airfoils to that of the SD 7080 (taken from Ref. 8). For the figure labeled Reynolds number 250,000 , the $\mathrm{C}_{\mathrm{d}}$ for the SD 7080 airfoil is taken at a Reynolds number of 200,000. Data for some BC airfoils at $12^{\circ}$ angle of attack was not available due to a large wake.

For a Reynolds number of 60,000, only the BC 3X92 has comparable drag with the SD 7080 airfoil. All other $\mathrm{BC}$ airfoils have larger drag, particularly at small angle of attack. At a Reynolds number of 250,000 , the BC 3 X92 also shows drag characteristics similar to the SD 7080. Although the BC 2125 and BC 3111 showed promising lift characteristics, the drag is significantly larger particularly at small angles of attack, which are more relevant at cruise conditions. These results show a unexpected sensitivity of airfoil drag to thickness of the airfoil particularly at low 
Reynolds numbers. It follows that a thin BC-type airfoil would be a more suitable replacement for existing thin conventional airfoils.
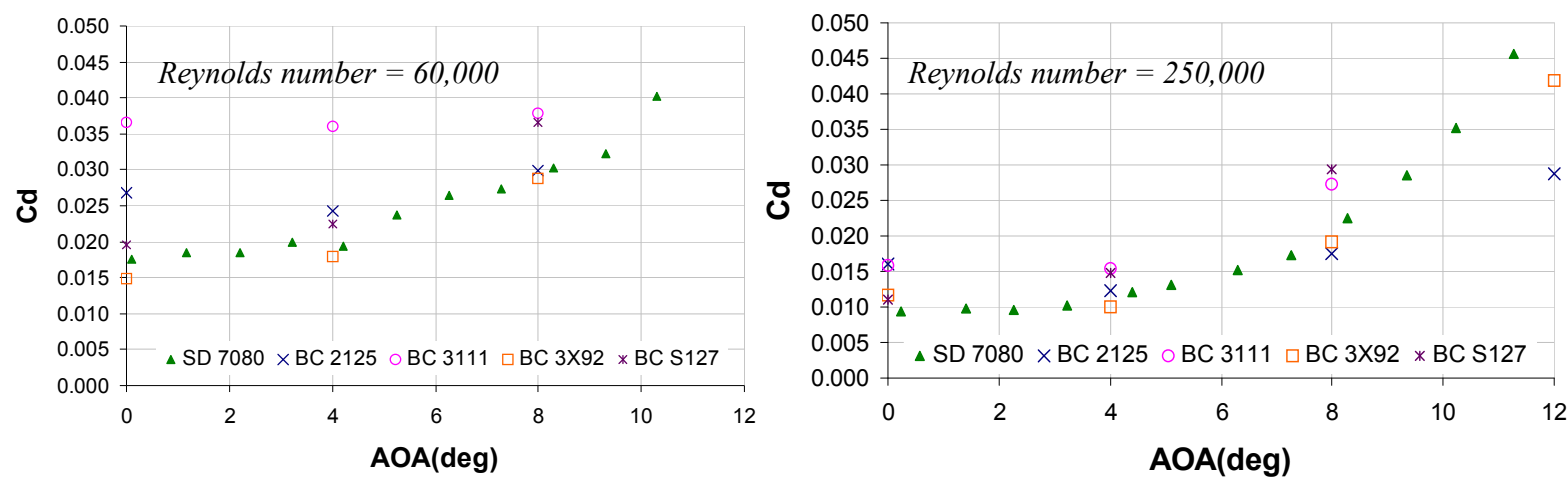

Figure 12. Drag characteristics of the BC airfoils compared to the SD 7080.

\section{Airfoil Suction Side Aerodynamics}

The flow on the suction side of the $\mathrm{BC}$ airfoils was examined via PIV. The purpose was to determine the presence and location of laminar separation bubbles (LSB). In order to find the LSBs, PIV-measured mean velocity profiles at every $10 \%$ of the chord were computed and plotted. In addition, and instead of the mean velocity profiles at the leading edge, the mean velocity profiles at $1 \%$-chord upstream of the leading edge were also plotted. Downstream of the airfoil, the mean velocity profile at 5\%-chord from the trailing edge was also computed and plotted. The plots were started at about half a millimeter from the wall of the airfoil based on the interrogation window size used in the PIV image analysis software. Finally, all the PIV measurements were conducted at three angles of attack: 0, 4 and 8 degrees; and at two Reynolds numbers of 60,000 and 200,000. In this section, mean velocity profiles will be shown only at chord locations with evidence of LSB. In addition, velocity profiles at the two closest locations both upstream and downstream of each of the above-mentioned chord locations were also graphed on a single plot. All of the resultant plots confirm that the recorded data were consistent.

\section{BC 2125 Airfoil}

At a low Reynolds number of 60,000 , the flow over the airfoil is separated at $70 \%, 80 \%$ and $90 \%$ of the chord at 0 -degrees angle of attack. The bubble appears at about $60 \%$-chord at 4-degrees angle of attack (shown by the dotted oval in Fig. 13a). There is no evidence of LSB at 60\%-chord and 8-degrees angle of attack.
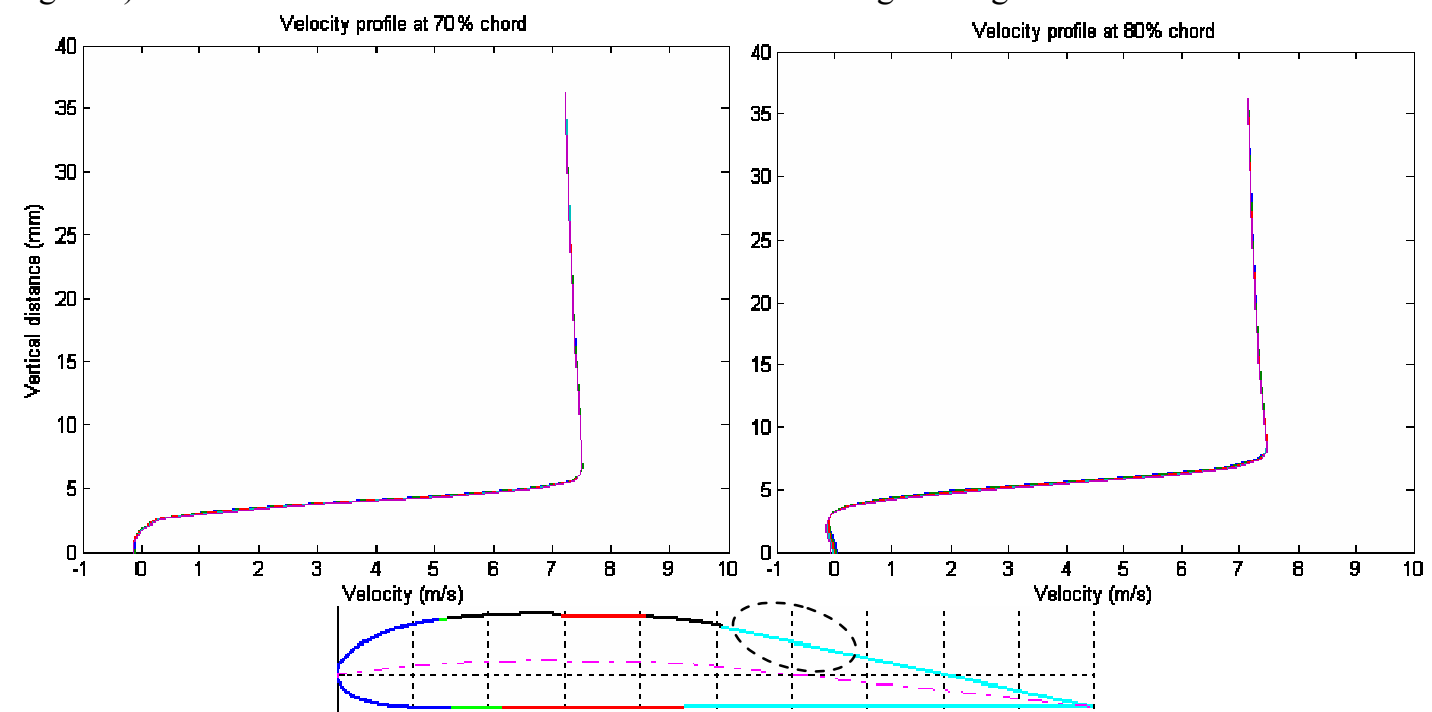

Figure 13a. Selected velocity profiles of the BC 2125 airfoil. Left and right figures show the velocity profiles at 0 degrees angle of attack for chord location of $70 \%$ and $80 \%$ respectively. The region with separated flow is generally enclosed by the dotted oval on the BC 2125. Reynolds number: 60,000. 

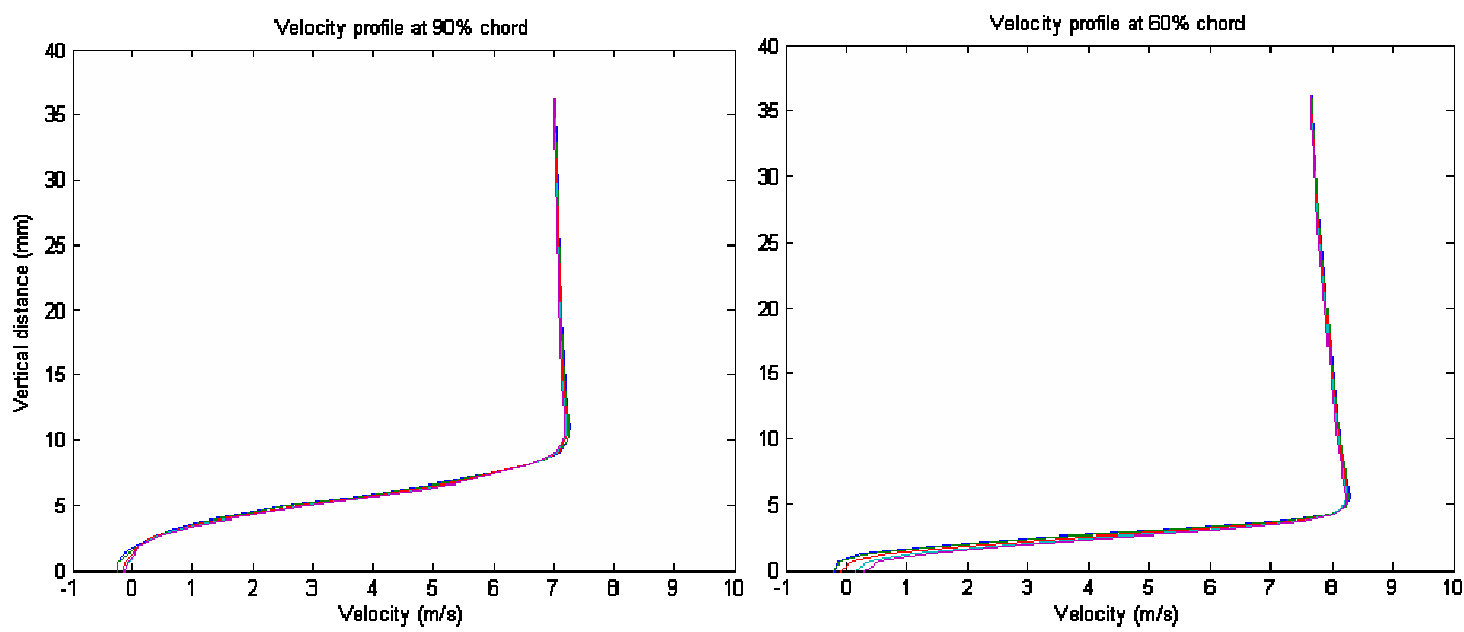

Figure 13b. Selected velocity profiles of the BC 2125 airfoil. Left figure shows the velocity profiles at 0 degrees angle of attack for chord location of $90 \%$ and right figure shows the velocity profile at 60\%-chord, 4 degrees angle of attack. Reynolds number: 60,000

As mentioned, each of the plots above consists of five velocity profiles; two upstream and two downstream of the specified chord location plus that at the specified chord location. The downstream span of these five locations is a fraction of a millimeter in the flow, and therefore the mean velocity profiles are not expected to vary significantly. With reference to Fig. 12, the drag curve of the BC 2125 at a Reynolds number of 60,000, the reduction in the region with separated flow (from spanning $70-90 \%$ to around $60 \%$ ) at 4-degrees angle of attack might account for the drop in $\mathrm{C}_{\mathrm{d}}$ observed. No LSB was observed at a Reynolds number of 200,000.

\section{BC 3111 Airfoil}

At 0 degrees angle of attack and a Reynolds number of 60,000 , the flow over the airfoil is separated at $70 \%, 80 \%$ and $90 \%$ of the chord. No evidence of LSB can be found for the higher angles of attack.
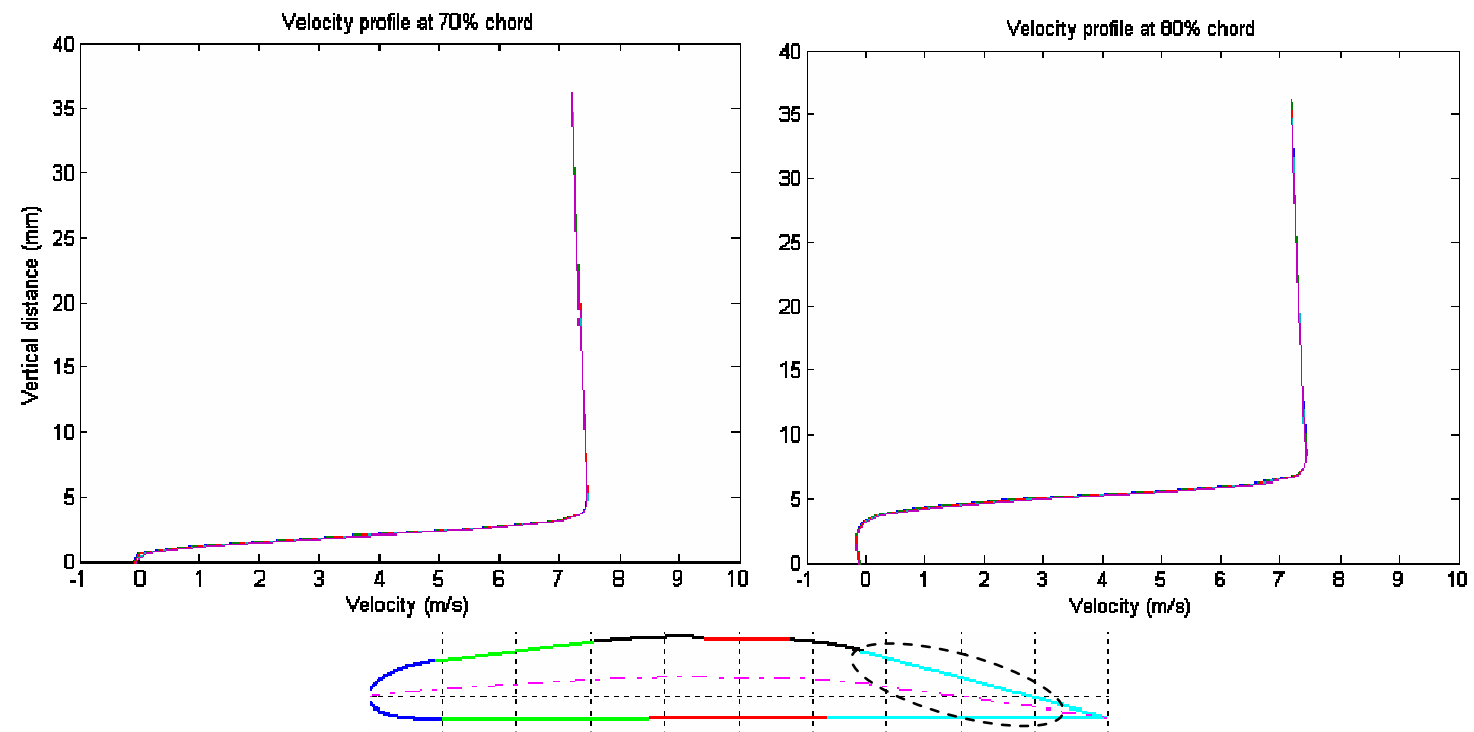

Figure 14a. Selected velocity profiles of the BC 3111 airfoil. Left and right figures show the velocity profiles at 0 degrees angle of attack for chord location of $70 \%$ and $80 \%$ respectively The region with separated flow is generally enclosed by the dotted oval on the BC 3111 .

American Institute of Aeronautics and Astronautics 


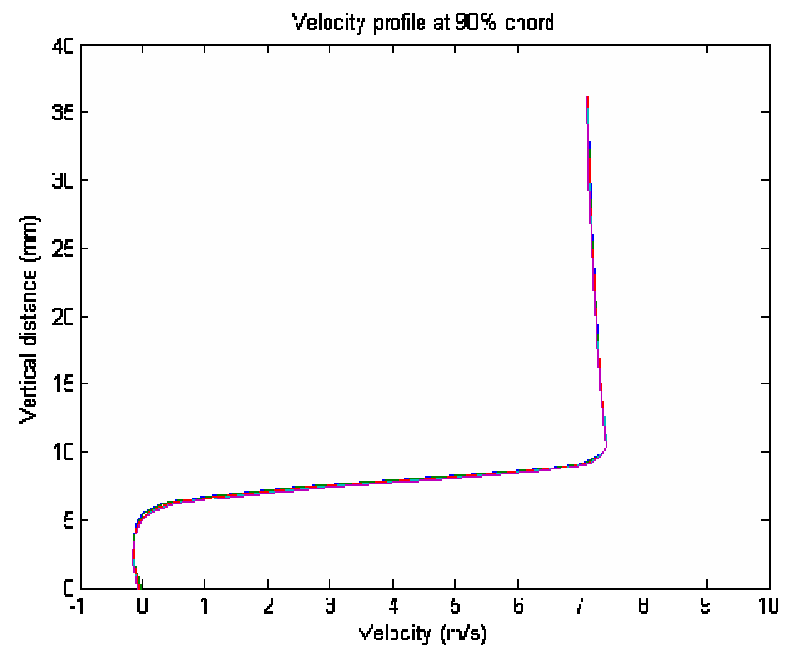

Figure 14b. Selected velocity profiles of the BC 3111 airfoil. The velocity profiles at 0 degrees angle of attack for chord location of $90 \%$ are shown.

The drag curve of the BC 3111 shows a less pronounced but observable dip in $\mathrm{C}_{\mathrm{d}}$ at an angle of attack of 4 degrees for a Reynolds number of 60,000. This is similar to the $\mathrm{BC} 2125$ airfoil and might be due to the reduction in size of the LSB. However, it is not clear if this reduction has a role to play for the sudden increase in lift curve slope from 1-4 degrees angles of attack. A LSB was not observed for 200,000 Reynolds number.

\section{BC 3 X92 Airfoil}

For a Reynolds number of 60,000 , at 0 degrees angle of attack, the flow at $80 \%$ chord is separated. At 4-degrees angle of attack, the LSB has moved upstream to about $60 \%$ chord. There is no evidence of separated flow at 8 degrees angle of attack.

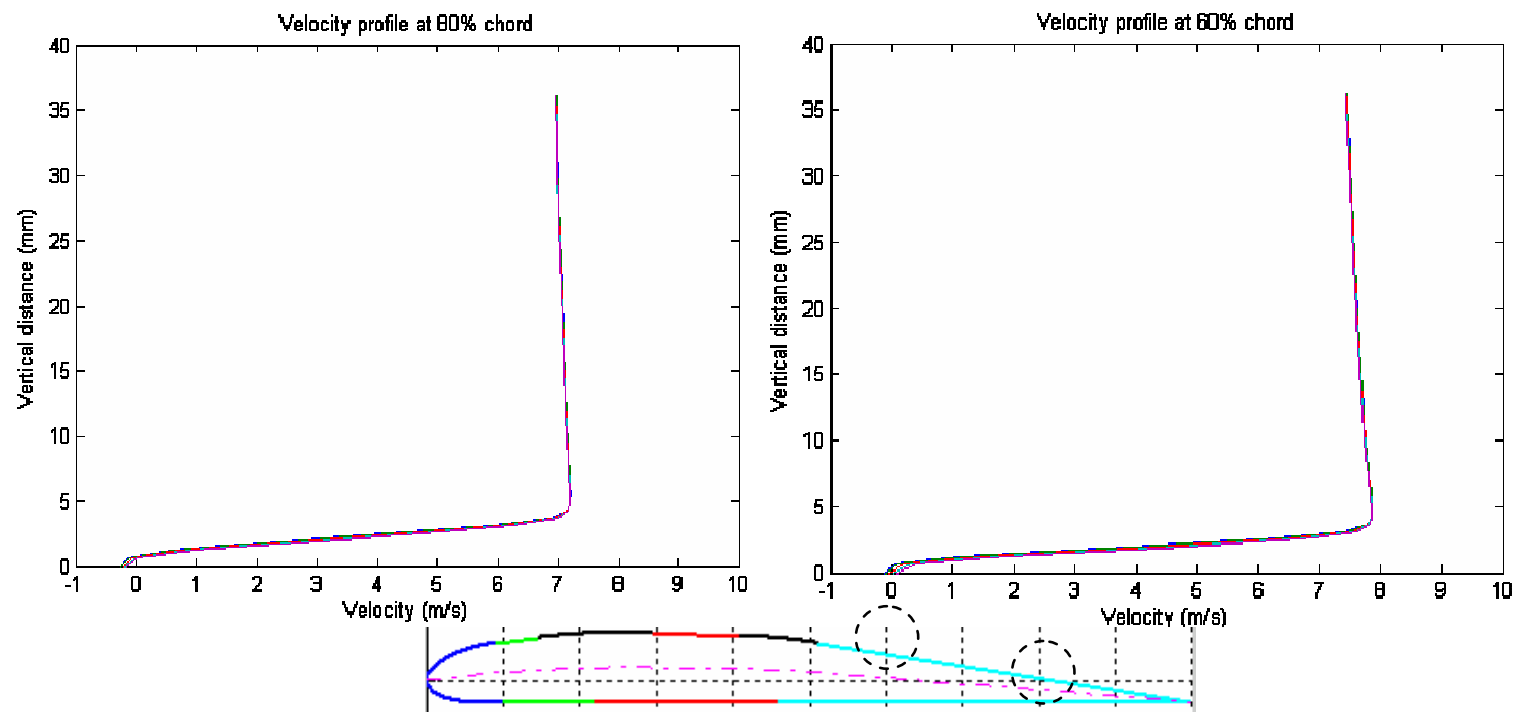

Figure 15. Selected velocity profiles of the BC 3 X92 airfoil. Left figure shows the velocity profile at 0 degrees angle of attack for chord location of $80 \%$ and the right figure shows that at 4 degrees angle of attack for $60 \%$ chord. The region with separated flow is generally enclosed by the dotted ovals on the BC $3 X 92$.

The upstream motion of the LSB at 60,000 Reynolds number does not seem to have an observable impact on the lift and drag characteristics of the airfoil. Again, at the higher Reynolds number of 200,000, there is no evidence of LSB. 


\section{BC S127 Airfoil}

For a Reynolds number of 60,000 , there is separated flow at $90 \%$ chord at 0 degrees angle of attack. As the angle of attack is increased to 4 and 8 degrees, this rear separation location vanishes and separated flow is instead observed at $20 \%$ chord.

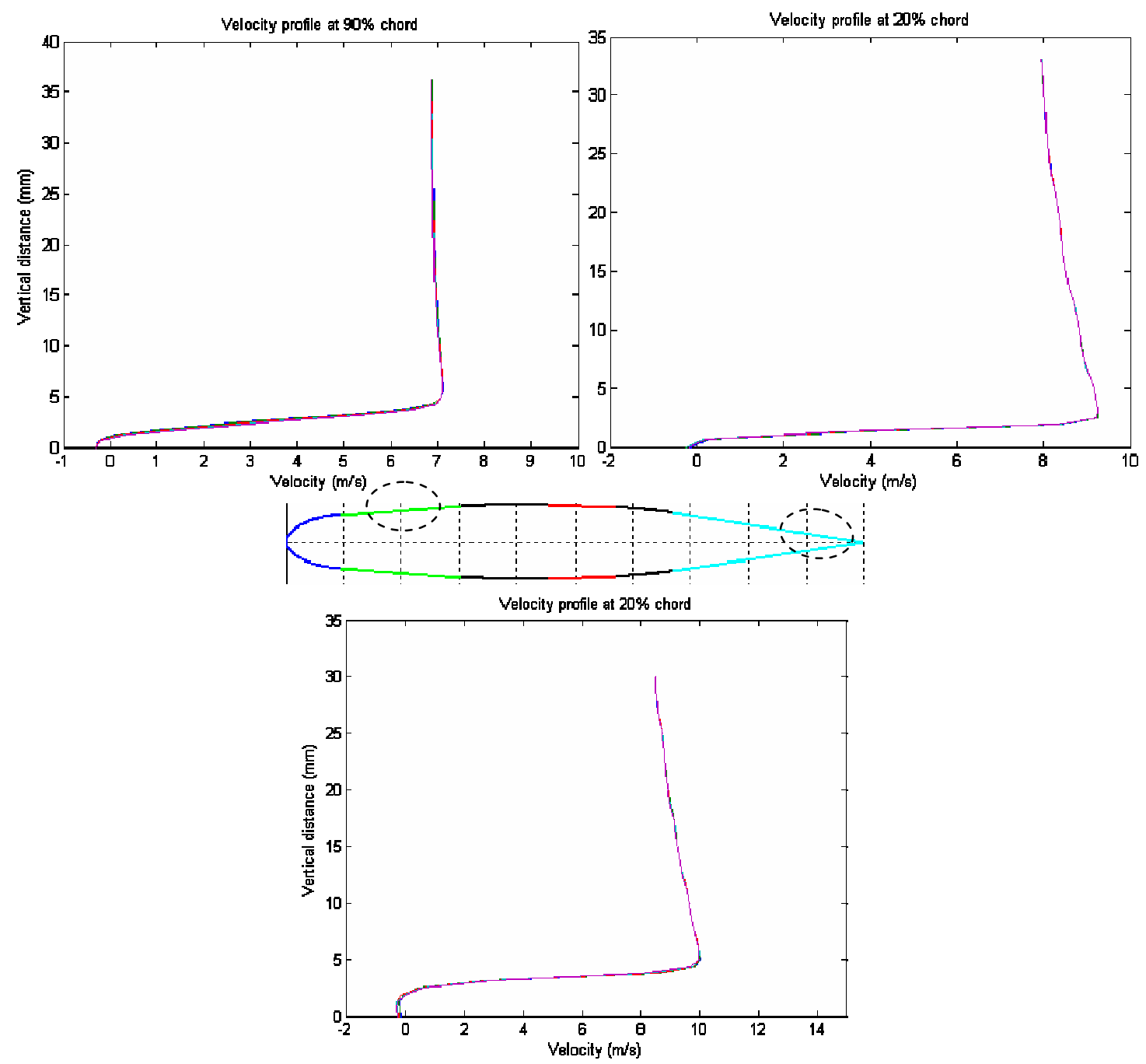

Figure 16. Selected velocity profiles of the BC S127 airfoil. From top left to bottom, the velocity profiles are shown for 0, 4 and 8 degrees angle of attack at 90\%, 20\% and 20\% chord respectively. The region with separated flow is generally enclosed by the dotted lines on the BC S127.

With reference to Fig. 10, at 60,000 Reynolds number, there is a pronounced reduction in the lift curve slope at around 4-degrees angle of attack. This might be related to the formation of the LSB near the suction peak at the front of the airfoil. At a higher Reynolds number of 200,000, there is again no indication of separated flow and the lift curve slope remains fairly constant up to stall. From all the PIV data, LSBs are only detected at the lower Reynolds number of 60,000 on the most rearward flat panel of all the airfoils, in addition the symmetrical BC S127 airfoil also has a LSB at its first panel.

\section{Comparison of XFOIL Predictions to Measured Data}

All of the experimental data were collected for the airfoils that were initially selected based on their predicted performance in XFOIL. XFOIL is widely-used, in academia and parts of industry for quick preliminary estimates of airfoil performance due to its ease of use and versatility. It is of interest to compare the results from the wind-tunnel experiments to ascertain the accuracy of XFOIL's predictions. 
In this study, comparisons were made based on the (predicted versus measured) lift of the airfoils and the (predicted versus measured) locations of the laminar separation bubbles. At the range of Reynolds numbers considered, LSBs are known to exist and they affect the lift characteristics of the airfoils. This is discussed in Ref. 9 where different airfoils were studied at a range of Reynolds number from 60,000 to 300,000 and their lift curves were given various classifications according to their shapes. The various categories are: "Recover", "Normal", "Drop", "Jump" and "Drop \& Jump". 9 The following figure is reproduced from Ref. 9 to illustrate the categories of the airfoils proposed by the authors.

Following Lee et al. ${ }^{9}$ the shape of the airfoils' lift curve can be related to the existence of the LSBs.

Therefore, it is
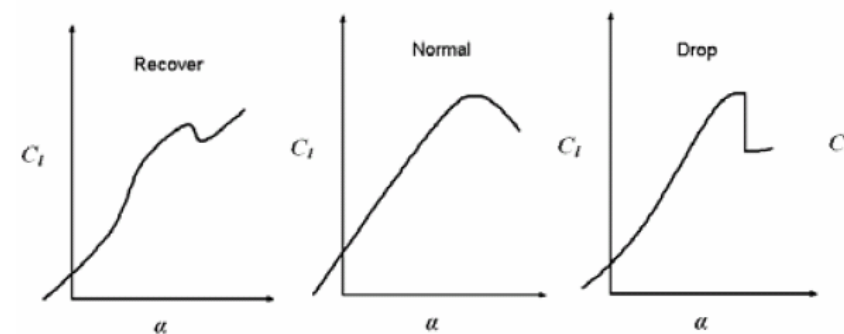

$\alpha$

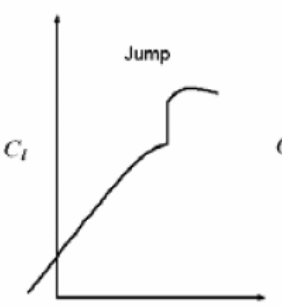

$\alpha$

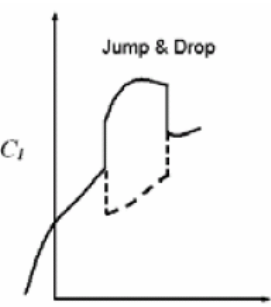

$\alpha$

informative to examine at how XFOIL fairs in predicting both lift and LSB characteristics. The correlation between the existence of LSBs and changes the airfoil's lift characteristics prompts the following discussion to be grouped according to the four different airfoils, each with its lift and LSB characteristics discussed in tandem. Owing to its versatility, XFOIL is able to generate large amounts of data. One parameter that can be varied is the log of the amplification factor of the most-amplified frequency that triggers transition or " $\mathrm{N}_{\text {crit }}$ ". This parameter can be changed to generate data sets that correspond to different disturbance levels in wind tunnels. The default $\mathrm{N}_{\text {crit }}$ value is 9 and it is prescribed for an "average wind tunnel". An attempt to match the $\mathrm{N}_{\text {crit }}$ value with the wind tunnel turbulence intensity did not improve results significantly. Hence, the following comparisons are only made for the default $\mathrm{N}_{\text {crit }}$ value.

\section{A. BC 2125 Airfoil}

The following graphs in Fig. 18 show the comparisons between the lift measured in the wind tunnel and the predicted lift from XFOIL.
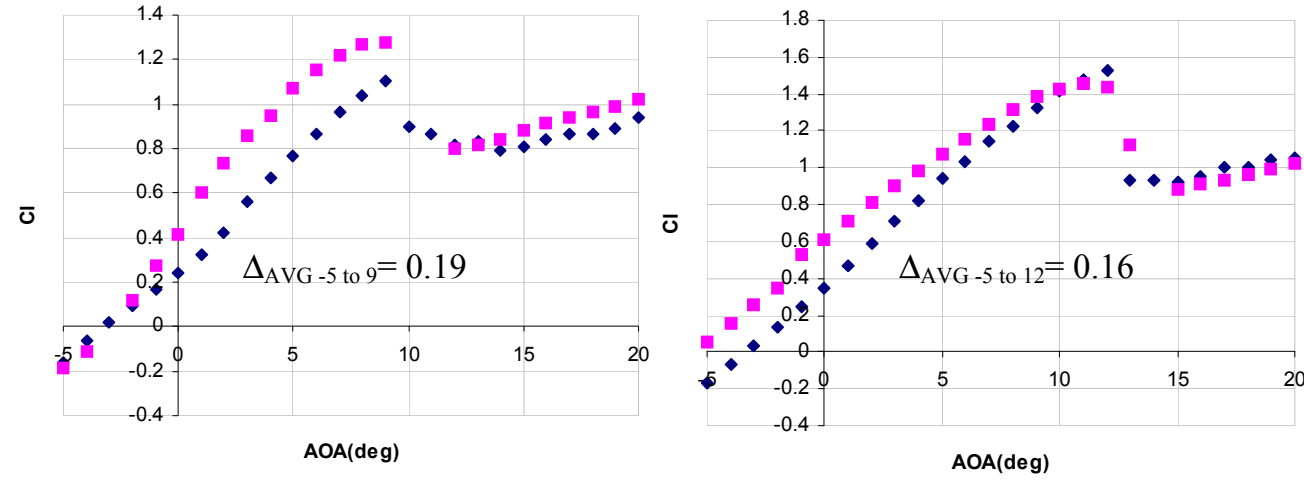

Figure 18a. Comparison of lift curves based on wind tunnel test data and XFOIL simulation for the BC 2125 airfoil for Reynolds numbers of 60,000 (left) and 100,00 ( right). An average difference, $\Delta$, of the $C_{l}$ values is calculated over the pre-stall region, indicated by the angles of attacks in the subscript. The angle of attack at which stall occurs is determined via the wind tunnel results.. 

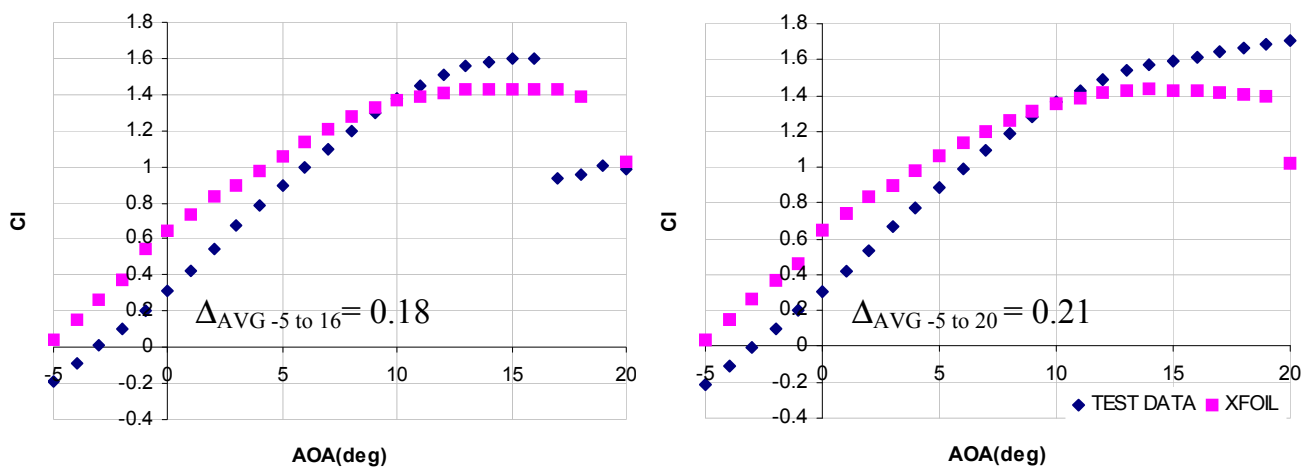

Figure 18b. Comparison of lift curves based on wind tunnel test data and XFOIL simulation for the BC 2125 airfoil of Reynolds numbers of 200,000 (left) and 250,000 (right). An average difference, $\Delta$, of the $C_{l}$ values is calculated over the pre-stall region, indicated by the angles of attacks in the subscript. The angle of attack at which stall occurs is determined via the wind tunnel results.

It can be seen that the trend of the lift curve is generally accurate; however, the lift is mostly over-predicted in the pre-stall region for all Reynolds numbers. It is interesting to note that XFOIL predicts the abrupt (hard) stall characteristic in the lower Reynolds numbers $(60,000$ and 100,000) and the plateau lift region for the higher Reynolds numbers. In this lift plateau, however, XFOIL under-predicts the lift. According to Ref. 9, most airfoils exhibit a "Recover" trend. However, the "Recover" trend is only barely noticeable on the lowest Reynolds number lift curve while there is an obvious "Drop" characteristic at stall.

From Fig. 13, PIV data shows that the flow was separated from $70 \%$-chord onwards at $0^{\circ}$ angle of attack and Reynolds number of 60,000 . In addition, PIV showed the presence of a bubble at about $60 \%$-chord at $4^{\circ}$ angle of attack but not at $8^{\circ}$. PIV data also indicated that there were no LSBs for a Reynolds number of 200,000 . In terms of the XFOIL simulations, a similar zone of separated flow was also observed at $0^{\circ}$ angle of attack and Reynolds number of 60,000 but it started further upstream at $43 \%$-chord. XFOIL data suggests that LSBs are persistent through most angles of attack for both cases of Reynolds numbers, in contrast to the measured data. Fig. 19 compares the XFOIL predicted LSB locations versus measurements via PIV at the angles of attack that the measurements were carried out.

A popular classification of LSBs follows that developed by the author of Ref 10. LSBs can be differentiated into short or long bubbles; the former has little effect on the overall performance of an airfoil whereas the long bubble tends to interact with the external flow and appreciably alter the pressure distribution over the suction side of the airfoil, hence, affecting its performance. ${ }^{10}$ In addition, the short bubbles are usually closer to the leading edge while the long bubbles are some distance away from the leading edge.

In terms of the PIV results, a bubble was only observed at a Reynolds number of 60,000 and at $4^{\circ}$ angle of attack. The LSB was not present at $0^{\circ}$ and it has disappeared at $8^{\circ}$ for the same flow condition. The corresponding lift curve did not exhibit any drastic changes from $0-8^{\circ}$ angle of attack, implying that the bubble observed did not impact the overall performance significantly

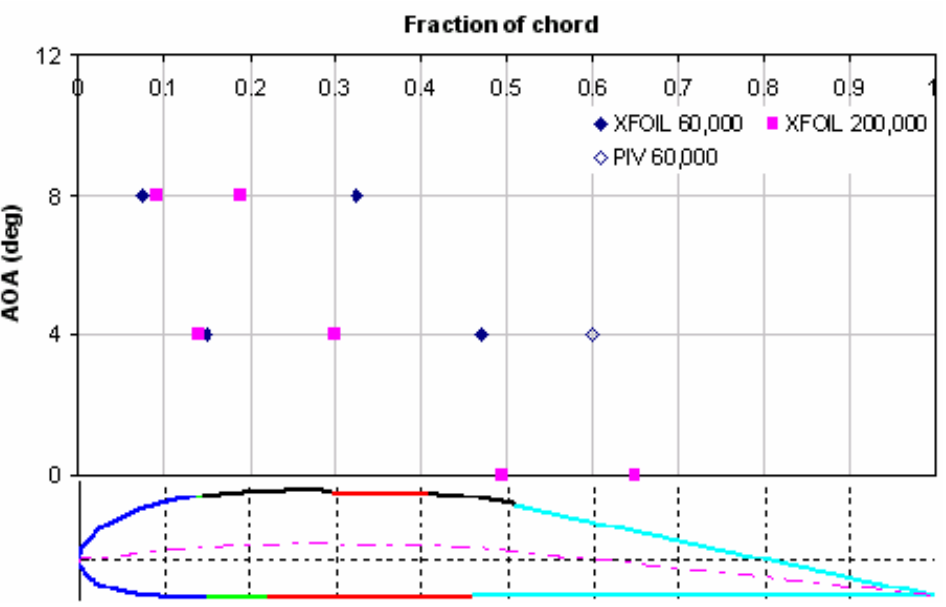

Figure 19. Predicted versus measured BC 2125 bubble locations for Reynolds numbers $\mathbf{6 0 , 0 0 0}$ and 200,000. XFOIL results show the span of the bubble; the leftmost point for a type of data point marks the head of a bubble and it extends to the rightmost point. PIV data show only discrete locations where the bubble was detected. and that it is a "short" bubble. However, the PIV data shows that it occurs some distance downstream of the leading edge. 


\section{B. BC 3111 Airfoil}

The BC 3111 airfoil has three flat panels on its suction side and has moderate maximum-thickness of $11.1 \%$ of its chord. During its design, it was noted that the lift curves have strong kinks that result in changes to its slope, as seen in the XFOIL data shown below. Wind tunnel data shows some evidence of these kinks, mostly at the lower Reynolds numbers of 60,000 and 100,000. Fig. 20 below compares the lift curves from XFOIL and wind tunnel data.
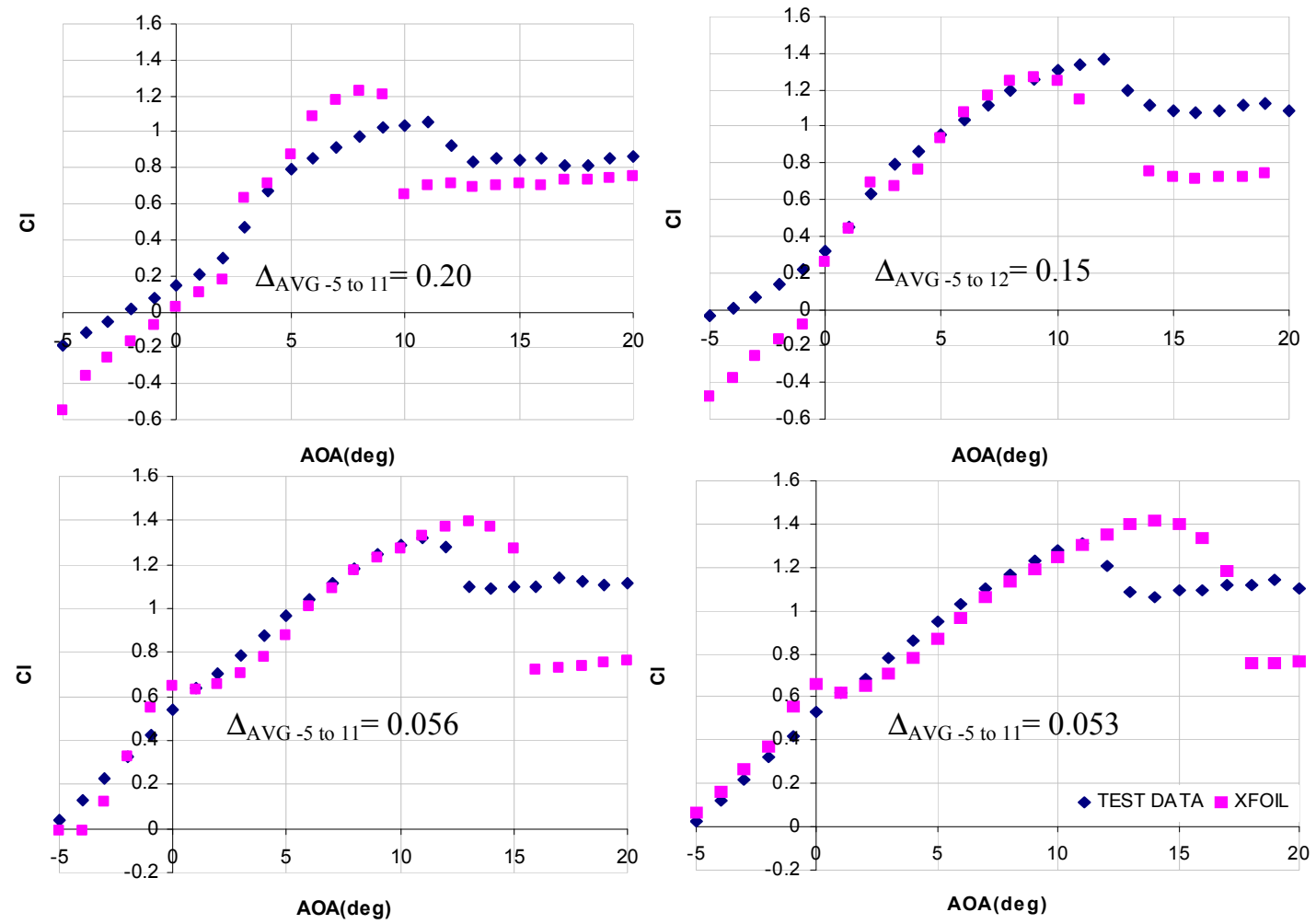

Figure 20. Comparison of lift curves based on wind tunnel test data and XFOIL simulation for the BC 3111 airfoil. Reynolds numbers of 60,000 (top left), 100,00 (top right), 200,000 (bottom left) and 250,000 (bottom right).

The comparisons show that XFOIL predicts the trend of the lift curves well, again. The average difference in the predicted versus measured lift values for the lower Reynolds numbers of 60,000 and 100,000 are approximately the same as the BC 2125 airfoil, in the range of 0.15 to 0.2 . However, the XFOIL prediction is remarkably close to the measured data for the higher Reynolds numbers. In this case, the shortcoming is the prediction of the onset of stall in which XFOIL overpredicts the stall angle of attack. The "Recover" trend is strong in the lower Reynolds numbers and all four plots show the "Drop" characteristic at stall too.

With reference to Fig. 14 and Fig. 21, none of the bubbles that XFOIL predicted

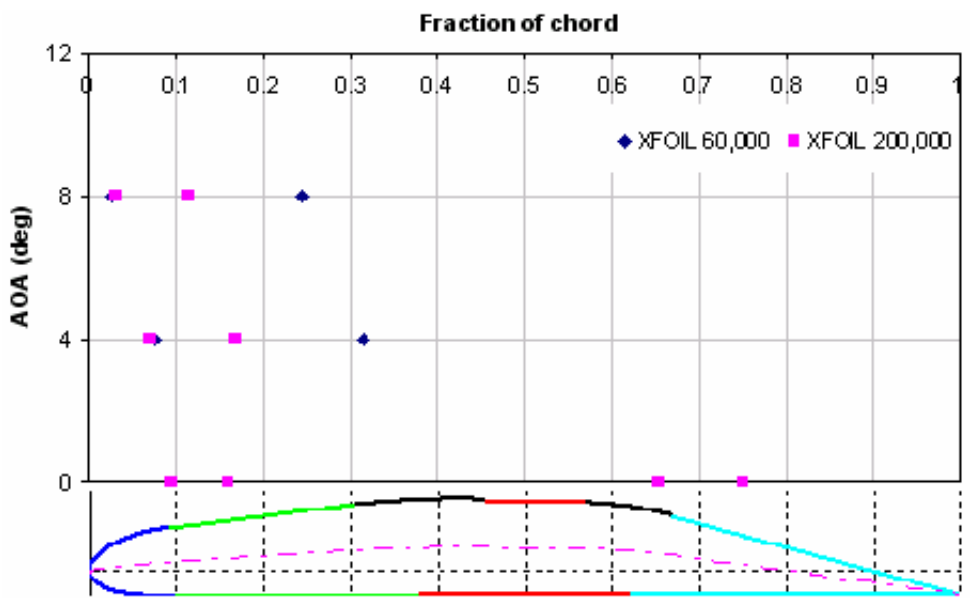

Figure 21. Predicted versus measured BC 3111 bubble locations for Reynolds numbers 60,000 and 200,000. XFOIL results at Reynolds number of 200,000 shows two bubbles at zero degrees $A O A$.

were detected in the PIV data. This links to the fact that not all the kinks in the lift curves, particularly in the region of 0-4 degrees angles of attack, are seen in 
the wind tunnel data. At $0^{\circ}$ angle of attack and Reynolds number of 60,000 , the flow on the airfoil was separated from 70\%-chord onwards whereas XFOIL predicted flow separation aft of 54\%-chord at the same condition. This prediction of an earlier separation by XFOIL is consistent with the case of the BC 2125 airfoil.

\section{BC 3X92 Airfoil}

Like the BC 3111 airfoil, the BC 3 X92 airfoil also has three flat panels on its top but it has a thinner maximumthickness of $9.2 \%$. Due to the reduced thickness, the initial performance prediction via XFOIL showed a fairly linear lift curve with no obvious kinks. This was also observed in the lift data obtained from the test results. Fig. 22 shows the comparisons for the XFOIL-predicted and measured lift curves.
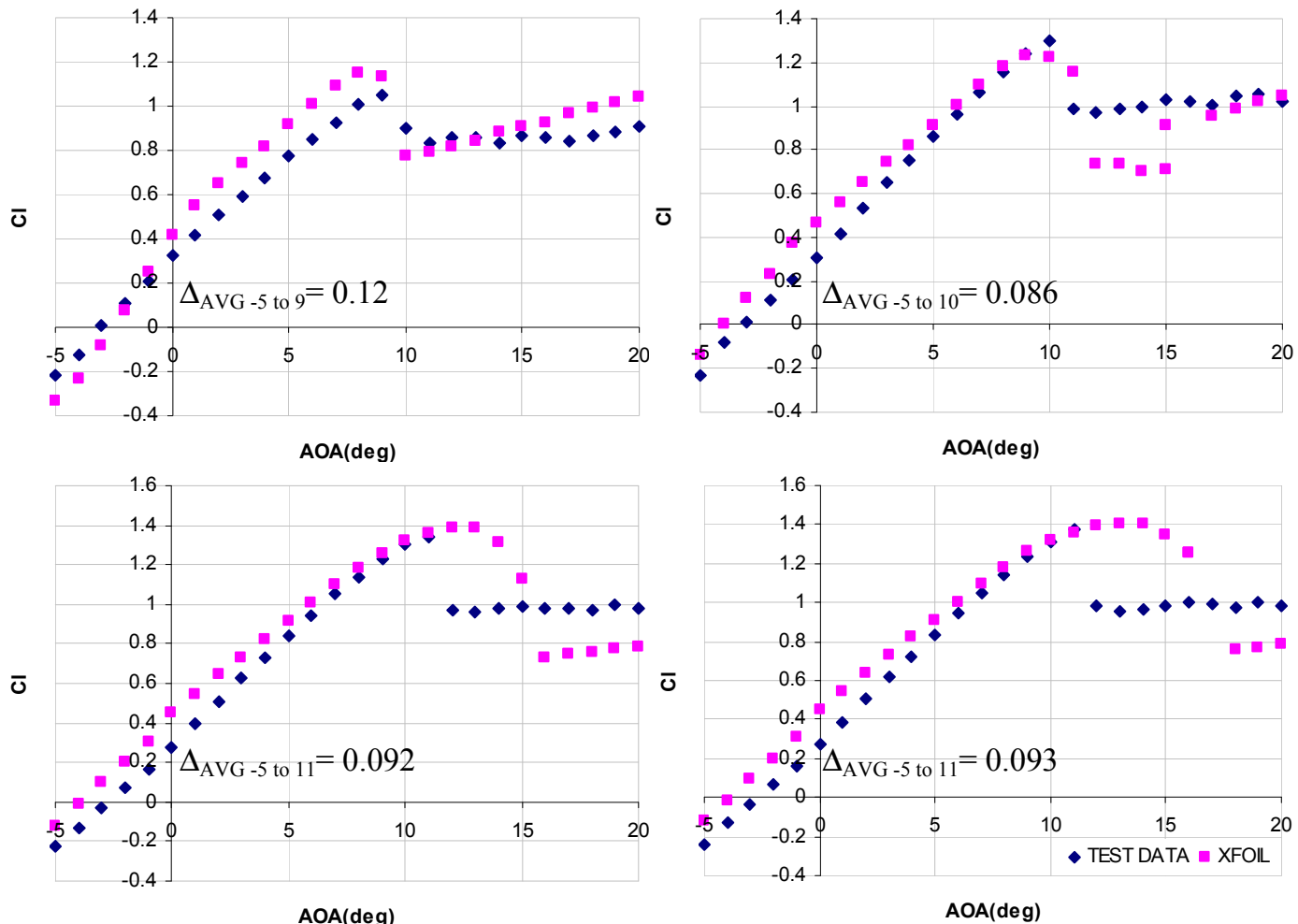

AOA(deg)

AOA(deg)

Figure 22. Comparison of lift curves based on wind tunnel test data and XFOIL simulation for the BC 3X92 airfoil. Reynolds numbers of 60,000 (top left), 100,00 (top right), 200,000 (bottom left) and 250.000 (bottom right).

The XFOIL-predicted lift is very close in trend and value to the actual lift measured in the wind tunnel for almost all four Reynolds numbers. The average difference between the XFOIL results and the wind tunnel measurements is better than the two previous airfoils. The airfoil exhibited the "Drop" characteristic at stall; however, the prediction of stall onset was inconsistent.

LSBs predicted by XFOIL at a Reynolds number of 60,000 spanned significant portions of the airfoil's top surface. The corresponding PIV measurements show that LSBs are indeed present but to a smaller extent at 0 and 4 degrees angles of attack (Fig. 23). This probably contributes to the

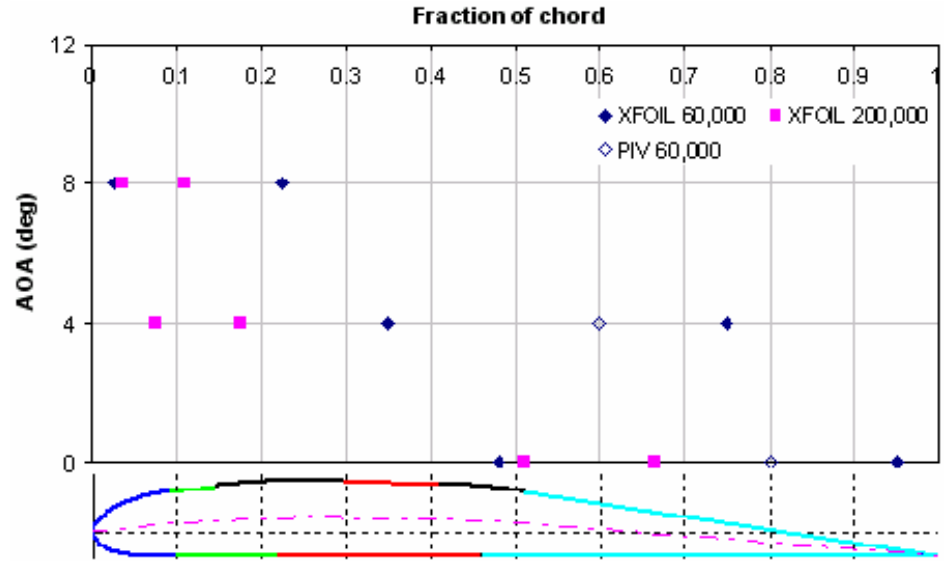

Figure 23. Predicted versus measured BC 3X92 bubble locations for Reynolds numbers 60,000 and 200,000 . greater accuracy of the XFOIL-predicted lift data, compared to the previous two airfoils at lower Reynolds numbers. Again, the presence of the LSB does not 
seem to have any obvious effects on the lift curve and hence they might be termed as short bubbles even though they are some distance from the leading edge. At the higher Reynolds number of 200,000, PIV data shows that LSBs are absent, in contrast to what XFOIL predicts.

\section{BC S127 Airfoil}

The BC S127 airfoil is symmetrical and also has the largest maximum-thickness of all the airfoils tested (12.5\% chord). The onset of stall for this airfoil is fairly early and most of the data presented in Fig. 24 are in the post-stall regime. In this region, the agreement between XFOIL and the measured data is not good but the agreement in
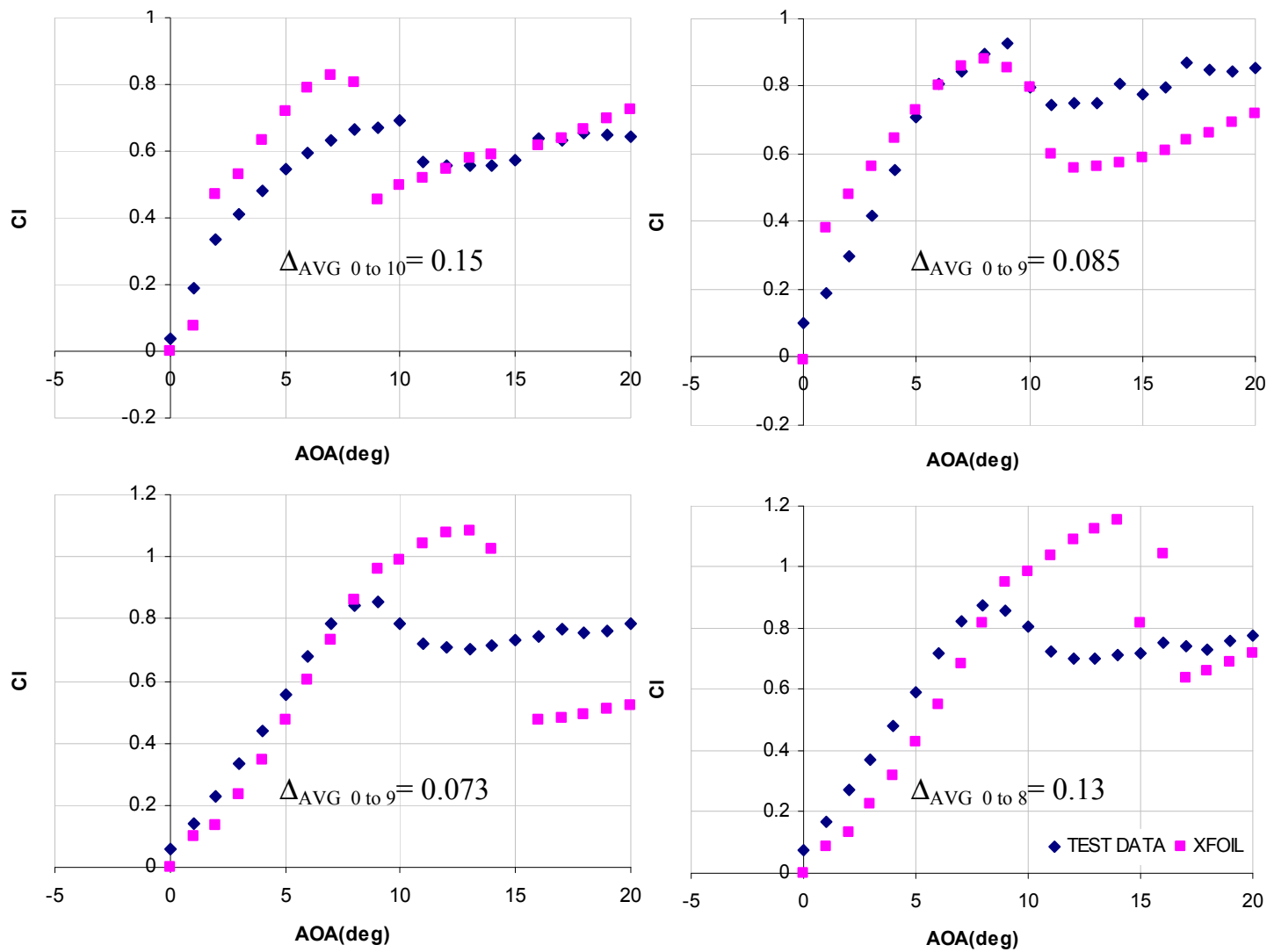

Figure 24. Comparison of lift curves based on wind tunnel test data and XFOIL simulation for the BC S127 airfoil. Reynolds numbers of 60,000 (top left), 100,00 (top right), 200,000 (bottom left) and 250,000 (bottom right).

the pre-stall region is consistent with the other airfoils' comparisons. The trend is well-predicted, even the stall angle of attack at the lower Reynolds numbers 60,000 and 100,000 but it is poorly predicted at the higher Reynolds numbers. XFOIL-predicted LSB, at a Reynolds number of 60,000 , spans the nose of the airfoil and part of this bubble is also detected in the PIV measurements. The bubble measured in the PIV data is contained within the bubble size that XFOIL predicts as shown in Fig. 25. Their proximity to the nose of the airfoil suggests that they are short bubbles and hence there is no obvious effect on the lift curve. There is again an absence of LSB in the wind tunnel PIV visualization at a Reynolds number of 200,000,

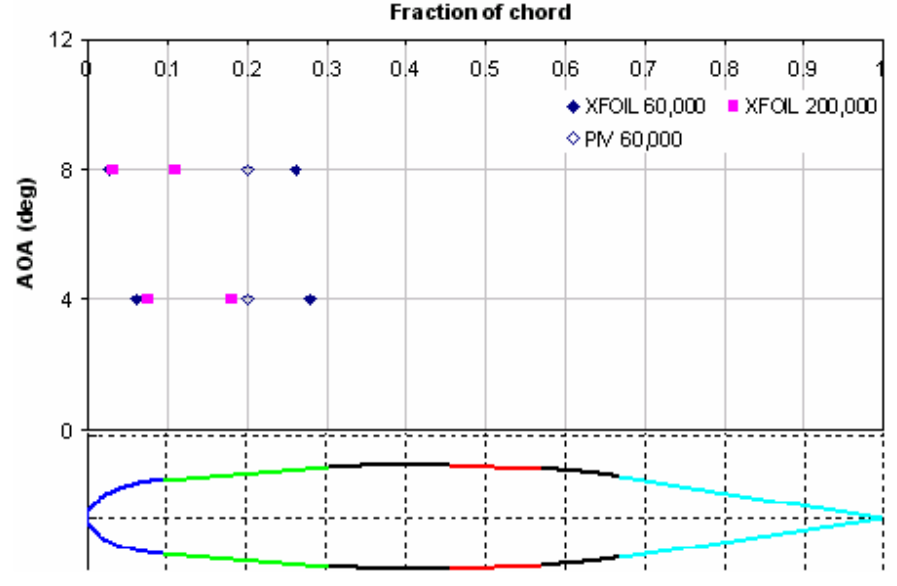

Figure 25. Predicted versus measured BC S127 bubble locations for Reynolds numbers 60,000 and 200,000 . 
unlike what was predicted by XFOIL.

Overall, the ability of XFOIL to predict the trend of the lift curves fairly accurately shows that it is a suitable tool for the initial design and evaluation. The average difference presented above for the $\mathrm{BC}$ airfoils should serve as a guideline to applying an uncertainty band about XFOIL's calculated values. With this uncertainty band, designers can consider their design and its performance in a more realistic sense while still reaping the benefits of XFOIL's versatility and efficiency. However, the inability of XFOIL to accurately predict laminar to turbulent transition, and the characteristics of LSBs mean that more work is needed to make better use of XFOIL in this aspect (even though this inadequacy is anticipated due to the simplicity behind XFOIL's turbulence model).

\section{Conclusion}

There is renewed interest in solar-powered air vehicles due to recent advances in solar cell technology and a need for long-endurance unmanned flight system. Airfoils consisting of flat panels, which can easily accommodate solar cells, joined by circular arc sections, and an elliptical nose have been investigated. A large number of airfoil configurations were evaluated using XFOIL and the four airfoils with better performance were fabricated for testing and design validation. The airfoils were tested in a $2^{\prime} \times 2$ low-turbulence wind tunnel; the lift of the airfoils was measured via a force balance, whereas the drag was calculated from mean velocity wake profiles measured using Particle Image Velocimetry. In addition, PIV velocity measurements in the boundary layer on the suction side of the airfoils were used to identify laminar separation bubbles. The lift produced by the cambered BC airfoils is generally higher than a conventional airfoil such as the SD 7080 at a range of Reynolds numbers from 60,000 to 250,000. Stall for the cambered $\mathrm{BC}$ airfoils occurs at a smaller angle of attack, and the maximum lift coefficient is significantly higher than for the SD 7080 airfoil. Drag characteristics of the BC 3111 show that it has higher drag than the SD 7080 at Reynolds numbers of 60,000 and 250,000. The BC 2125 has a higher drag than the SD 7080 at a Reynolds number of 60,000; but the drag is comparable to the SD 7080 at a Reynolds number of 250,000. The thinnest airfoil is the BC 3X92, which has the same thickness as the SD 70980 (9.2\%). The BC 3 X92 shows lower drag than the SD 7080 at both Reynolds numbers. The symmetrical BC S127 has modest lift and higher drag compared to the SD 7080. From the analysis of the suction side boundary layers, laminar separation and laminar separation bubbles are common on the final flat panel of the airfoils. The extent of the laminar separation bubbles might affect the lift curve slope of the airfoil and its drag $^{9}$. However, the PIV data only showed laminar separation bubbles at the lower Reynolds number of 60,000 but not at 200,000. In contrast, XFOIL predicts the presence of laminar separation bubbles throughout the range of Reynolds numbers from 60,000 to 200,000. The present results show that flat panel airfoils, like the BC 3X92, have potentially higher lift and lower drag compared to conventional cambered airfoils. Further refinement in the details of the basic elements of the flat-paneled airfoils can lead to optimal designs. In designing such unconventional airfoils, XFOIL can be used as a preliminary design and evaluation tool due to its accuracy in predicting the lift characteristics. However transition calculations require further refinement. Despite this, XFOIL is able to predict the trends of the lift curve fairly accurately at most Reynolds numbers. On the experimental study, more coordinate measurements on the manufactured airfoils would be helpful to verify consistency of the airfoil shape. The use of polished-acrylic airfoil models enabled Particle Image Velocimetry measurements in the boundary layer of the airfoils. Future experimental studies should investigate the laminar-toturbulent transition in the airfoil boundary layers to provide a better the understanding of laminar separation bubbles, which are critical in low Reynolds number airfoils particularly for flat paneled airfoil.

\section{Acknowledgments}

We acknowledge the help of Terry Larrow, Chris Chartier, and Anthony Smith at the University of Michigan, Ann Arbor, for their assistance with manufacturing and testing of the airfoils. W. Chen would like to thank Defence Science \& Technology Agency for their financial support throughout his studies at the University of Michigan, Ann Arbor. He would also like to acknowledge the support of DSO National Laboratories in the writing and presentation of this paper. Finally, W. Chen expresses his deepest gratitude for the support and mentorship of Professor Luis Bernal and the Aerospace Engineering faculty, and the support of Loh Yu Xing; without these people this paper would not have been possible.

\section{References}


${ }^{1}$ Boucher, R. J., "History of Solar Flight," AIAA Paper 84-1429, AIAA / SAE / ASME $20^{\text {th }}$ Joint Propulsion Conference, Cincinnati, Ohio, June 11-13, 1984.

${ }^{2}$ MacCready, P. B., Lissaman, P.B.S., Morgan, W. R., and Burke, J. D., "Sun Powered Aircraft Design," AIAA Paper 810916, AIAA 1981 Annual Meeting and Technical Display, Long Beach, California, May 12-14, 1981.

${ }^{3}$ Bailey, M.D., and Bower, M.V., "High Altitude Solar Power Platform," NASA TM 103578, 1992.

${ }^{4}$ Sharma, A. K., Dwivedi, R., and Srivastava, S. K., "Performance Analysis of a Solar Array under Shadow Condition", IEE Proceedings- $G$, vol. 138, no. 3, pp. 301-306, June 1991.

${ }^{5}$ Drela, M., "Elements of Airfoil Design Methodology," Applied Computational Aerodynamics Progress in Astronautics and Aeronautics, vol. 125, pp. 167-189, 1990.

${ }^{6}$ Drela, M., "XFOIL: An Analysis and Design System for Low Reynolds Number Airfoils," Conference on Low Reynolds Number Aerodynamics, University of Notre Dame, Notre Dame, Indiana, June 1989.

${ }^{7}$ Raymer, D. P., Aircraft Design: A Conceptual Approach, $3^{\text {rd }}$ ed, AIAA Education Series, AIAA, Reston, Virginia, 1999.

${ }^{8}$ Selig, M.S., Donovan, J.F., and Fraser, D.B., Airfoils at Low Speeds, Soartech Publications, Virginia Beach, Virginia, 1989.

${ }^{9}$ Lee, C.S., Pang W.W., Srigrarom S., Wang D.B., and Hsiao F.B., "Classification of Airfoils by Abnormal Behaviour of Lift Curves at Low Reynolds Number," AIAA 2006-3179, AIAA $24^{\text {th }}$ Applied Aerodynamics Conference, San Francisco, California, June 5-8, 2006.

${ }^{10}$ Tani, I., "Low Speed Flows Involving Bubble Separations," Progress in Aerospace Sciences, vol. 5, pp. 70-103, Pergamon Press, Jan 1964. 